MERITOCRACY IN AMERICA: WAGES WITHIN AND ACROSS OCCUPATIONS

\author{
John Cawley \\ James Heckman \\ Edward Vytlacil
}

Working Paper 6446 


\title{
MERITOCRACY IN AMERICA: WAGES WITHIN AND ACROSS OCCUPATIONS
}

\author{
John Cawley \\ James Heckman \\ Edward Vytlacil
}

Working Paper 6446

http://www.nber.org/papers/w6446

\section{NATIONAL BUREAU OF ECONOMIC RESEARCH 1050 Massachusetts Avenue \\ Cambridge, MA 02138 \\ March 1998}

We thank Jennifer Boobar, Karen Conneely, and Mary Beth Wittekind for their helpful comments. Any opinions expressed are those of the authors and not those of the National Bureau of Economic Research.

(C) 1998 by John Cawley, James Heckman and Edward Vytlacil. All rights reserved. Short sections of text, not to exceed two paragraphs, may be quoted without explicit permission provided that full credit, including (C) notice, is given to the source. 
Meritocracy in America: Wages Within

and Across Occupations

John Cawley, James Heckman

and Edward Vytlacil

NBER Working Paper No. 6446

March 1998

\begin{abstract}
In The Bell Curve, Herrnstein and Murray argue that the U.S. economy is a meritocracy in which differences in wages (including differences across race and gender) are explained by differences in cognitive ability. In this paper we test their claim for wages conditional on occupation using a simultaneous model of occupation choice and wage determination. Our results contradict Herrnstein and Murray's claim that the U.S. labor market operates only on meritocratic principles.
\end{abstract}

John Cawley

Department of Economics

University of Chicago

1126 East 59th Street

Chicago, IL 60637

Edward Vytlacil

Department of Economics

University of Chicago

1126 East 59th Street

Chicago, IL 60637
James Heckman

Department of Economics

University of Chicago

1126 East 59th Street

Chicago, IL 60637

and NBER

jimh@cicero.spc.uchicago.edu 


\section{Introduction}

In The Bell Curve, Richard Herrnstein and Charles Murray argue that the U.S. economy is a meritocracy. (Herrnstein and Murray (1994), e.g. pp. 511-512.) Herrnstein and Murray do not explicitly define meritocracy, but their use of the term has two testable implications.

First, they suggest that meritocracy implies that individuals of different race or gender are treated equally in the labor market, with any apparent differences in wages across race and gender being due to differences in $g$, representing general intelligence or IQ. For example, Herrnstein and Murray write that "the racial difference [in 1989 wages] disappears altogether"(Herrnstein and Murray, 1994, p. 326.) in the National Longitudinal Survey of Youth (NLSY) when they control for age, IQ, and gender.

Second, Herrnstein and Murray suggest that their cognitive ability measure explains a large fraction of the differences in wages between individuals. They note that large residuals are common in wage regressions and speculate: "What then is this [wage] residual, this $X$ factor, that increasingly commands a wage premium over and above education? It could be a variety of factors...but...we believe that it includes cognitive ability." (Herrnstein and Murray, 1994, p. 97.) Herrnstein and Murray appear to be saying elsewhere in The Bell Curve that differences in their measure of cognitive ability are the dominant factor in predicting wages. For example, one section is entitled: "The End Result: Prosperity for Those Lucky Enough to be Intelligent". (Herrnstein and Murray, 1994, pp. 100-101.)

Elsewhere (see Cawley et al., 1997) we test and reject both of these claims. First, we find that ability is rewarded unequally in the labor market - workers of a given measured ability receive different wages depending on their race and gender, with these differences 
being statistically and numerically significant. Second, we find that Herrnstein and Murray overestimate the role of measured cognitive ability in explaining wage variance. In our previous paper, the marginal $R^{2}$ of our measures of cognitive ability (including $\mathrm{g}$ ) is between .118 and .179 , and when we control for human capital measures, it falls to between .034 and .011. Both of these results are robust to alternative specifications of cognitive ability. (See Cawley et al., 1996).

The effects of cognitive ability on wages can be classified into two categories: effects on wages within occupations, and effects on occupational choice. A potential weakness of our previous work is that we did not condition on occupation. Our previous work yields no information about whether Herrnstein and Murray's meritocracy hypothesis holds within occupations. For example, even if wages conditional on occupation could be perfectly predicted by ability, heterogeneous preferences for occupation could still cause wages in the labor market as a whole to be only weakly correlated with the cognitive ability measures. Our previous results are also consistent with the hypothesis that wages and ability are completely unrelated within occupations, but higher ability is associated with a preference for higher paying occupations. Thus, to evaluate Herrnstein and Murray's meritocracy hypothesis, it is critical to distinguish the effect of ability on wages within occupations from its effect on preferences for occupations.

In this paper, we examine whether the U.S. labor market is meritocratic within and across occupations. First, we test whether the labor market is meritocratic within occupations, without controlling for the effects of self-selection into occupation. Second, we estimate a simultaneous model of occupational choice and wage determination. Estimates from the simultaneous model will indicate whether the labor market is meritocratic within 
occupations, controlling for self-selection and allowing persons of different race and gender to differ in how they choose occupations. Using these results, we also decompose the effect of cognitive ability on wages into the fractions that operate through choice of occupation and through wages given occupation.

Our results do not support the claim that the U.S. is a meritocratic labor market. The wage paid for cognitive ability depends on the race and gender of the person in whom the ability is embodied. This is true conditional on occupation whether or not we control for selection into occupations. We also show that Herrnstein and Murray overestimate the predictive power of cognitive ability in wage regressions. Our measures of cognitive ability explain only a few percentage points of wage variance within each occupation. Combined, ten measures of cognitive ability plus human capital measures, unemployment rates, and region of residence account for less than a third of wage variance within each occupation.

\section{Our Sample}

Our empirical sample is based on the same survey used by Herrnstein and Murray: the National Longitudinal Survey of Youth (NLSY). The NLSY is designed to represent the entire population of American youth and consists of a randomly chosen sample of 6,111 U.S. civilian youths, a supplemental sample of 5,295 randomly chosen minority and economically disadvantaged civilian youths, and a sample of 1,280 youths on active duty in the military. All were between thirteen and twenty years of age in 1978 and were interviewed annually starting in 1979. The data include equal numbers of males and females. Roughly $16 \%$ of respondents are Hispanic and $25 \%$ are black. For our analysis, we restrict the sample to 
those not currently enrolled in school and those persons receiving an hourly wage between $\$ .50$ and $\$ 1000$ in 1990 dollars (all results of this paper are reported in 1990 dollars). In 1980 , NLSY respondents were administered a battery of ten intelligence tests referred to as the Armed Services Vocational Aptitude Battery (ASVAB). We describe the ASVAB subtests in Table 1.

Critical to an empirical examination of the meritocracy hypothesis is how to measure ability. The meritocracy hypothesis has no empirical content if no position is taken on how cognitive ability relates to characteristics observable to the econometrician. If individuals of different races but with the same measured ability receive the same wages, this would still be consistent with discrimination if the average level of unobserved cognitive ability was different across races. The meritocracy hypothesis of Herrnstein and Murray has empirical content because they specify a particular measure of cognitive ability, $g$, and implicitly specify that other measures of ability are either unimportant to wages or are conditionally mean independent of race and gender. This is a particularly restrictive formulation of ability, and we relax it by including both human capital measures and additional measures of cognitive ability in our analysis. (See Heckman (1995) for a discussion of these issues.)

We include other measures of cognitive ability in our analysis besides $g$. Herrnstein and Murray argue this single measure of cognitive ability is sufficient to predict outcomes. However, it has consistently been shown that in addition to $g$, other measures of cognitive ability are statistically significant (although modest in magnitude) in predicting outcomes.(See e.g., Cawley et al., 1997, Ree, Earles, and Teachout, 1994, and Ree and Earles, 1991.) ${ }^{1}$

In light of this, we use ten mutually orthogonal measures of cognitive ability, each of which is a linear combination of the ten ASVAB scores. In this way we use all of the information on 
cognitive ability contained in the ASVAB. ${ }^{2}$ To generate these measures of cognitive ability, we use principal components analysis, although principal factor analysis and hierarchical factor analysis produce essentially the same empirical results. The principal components method is least affected by sampling error,(Jensen, 1987, p. 91.) but the correlation between each pair of the three estimates of $g$ is .996.(Ree and Earles, 1991, p. 323.)

However, regardless of the method used, the degree to which cognitive ability is measured is determined by the constituent tests. Many features of personality and motivation are not captured by the ASVAB.

Because age at the time of the test influences performance on the test, we first residualize each of the ASVAB tests on age at the time of the test, separately by race and gender groups. ${ }^{3}$ The residuals were standardized to mean zero and variance one. Principal components were estimated from the standardized residuals. The principal components were standardized separately by race and gender to have mean zero and an interquartile range of one.

The first principal component or factor is $g$. The remaining principal components are sometimes refered to as specific factors, s. In the case of the principal components derived from the ASVAB test score battery, we find a second principal component which heavily weights the speeded subtests. Carroll (1993) describes this commonly found speeded intelligence factor as "Numerical Facility," reflecting the fact that the speeded tests usually require rapid arithmetic operations. It should be stressed, however, that principal components are mathematical constructs, and it can be misleading to describe principal components in terms of observed human skills. ${ }^{4}$

Ironically, while Herrnstein and Murray embrace $g$, they use a different (though highly correlated) measure of ability in their analysis: the Armed Services Qualification Test 
(AFQT) score, which is the sum of the ASVAB subtests Word Knowledge, Paragraph Comprehension, Arithmetic Reasoning, and Mathematics Knowledge. If AFQT is the best measure of general intelligence, then the first principal component $(g)$ should assign equal weights to each of the four subtests that constitute AFQT and assign zero weights to all other subtests. We do not find such a pattern. Table 2 lists the ASVAB weights for the first principal component; these weights suggest that while AFQT is highly correlated with $g(\rho=.829)$, it is a suboptimal measure of general intelligence, which suggests that Herrnstein and Murray may underestimate the effect of intelligence on social outcomes.

Table 2 also indicates that the first principal component is strikingly similar across race and gender. This has generally been found to be true for different racial populations that share the same language and culture.(Jensen, 1987, p. 99.) These loadings are similar to those produced if principal components are computed for the sample as a whole rather than separately for each race and gender group. In results not shown here, we reestimate all of the models of this paper using principal components computed for the whole population; all of the findings of this paper are robust to that alternative specification of ability.

Table 3 contains the proportion of variance in ASVAB test scores attributable to the principal components. The first principal component, $g$, is dominant in the ASVAB test score matrix-it explains between $55.2 \%$ and $70.6 \%$ of the variation in the test scores of each race-gender group. The amount of variance explained by $g$ depends upon the similarity of the tests and the range of ability of the persons constituting the sample. Jensen reports that across 20 independent correlation matrices comprising a total of more than 70 tests, the average percentage of variance accounted for by $g$ is $42.7 \%$ (with a range of $33.4 \%$ to 61.4\%).(Jensen, 1987, p. 98.) 
We classify all occupations as either white collar or blue collar. ${ }^{5}$ White collar workers are those working in sectors described by the U. S. Census as "Professional, Technical, and Kindred Workers," "Non-Farm Managers and Administrators," "Sales Workers," and "Clerical and Unskilled Workers." The only unskilled workers in the last group are those in white-collar positions, such as cashiers, file clerks, bill collectors, and messengers.

The mean principal component scores by race, gender, and occupation are listed in Table 4. For each race-gender group, the $g$ (i.e. the first principal component) of white collar workers is roughly half of an interquartile range higher than that of blue collar workers. Because the first principal component positively weights each ASVAB subtest, this unambiguously means that white collar workers scored higher on the subtests heavily weighted by $g$. For the second through tenth principal components, some ASVAB subtests are assigned negative weights and others positive weights; each principal component can be reconstructed using the negative of its ASVAB weights to explain an equal amount of ASVAB variance. For this reason, it is impossible (without more information than is contained in Table 4) to say whether white collar or blue collar workers scored higher on the subtests receiving weights which were large in magnitude (irrespective of sign) for the second through tenth principal components.

Table 5 lists mean ASVAB scores by occupation, race, and gender. For this table, the raw ASVAB scores are normalized to mean zero and interquartile range of one for the entire population. Within each race and gender group, white collar workers scored significantly higher on every ASVAB subtest. However, within each race and gender group, white collar workers have a larger advantage in subtests that appear to test white collar skills (general science, numerical operations, arithmetic reasoning, coding speed, mathematics knowledge, 
paragraph completion, and word knowledge) than in tests that appear to test blue collar skills (auto \& shop information, electronic information, and mechanical comprehension). Thus, choice of occupation appears to be driven by comparative advantage.

\section{Wage Equations}

For reference, we first present some results on wage equations without conditioning on occupation. ${ }^{6}$ We estimated the following model, suppressing individual subscripts:

$$
\begin{aligned}
W_{t} & =X_{t} \phi+\eta_{t} \\
E\left(\eta_{t} \mid X_{t}\right) & =0
\end{aligned}
$$

where $W_{t}$ is $\log$ wages at date $t . X_{t}$, our vector of regressors at date $t$, consists of the ten principal components, education, potential experience (See Mincer, 1974) (defined as age minus years of education minus 6), and indicator variables for region of residence, local and national unemployment rates, and the year that the wage was observed. ${ }^{7}$ We estimate this model using least squares run separately for each race and gender group. We assume that $\eta_{t}$ is independent across individuals, but not necessarily independent across time for a given individual. We use Eicker-White standard errors, generalized for panel data, to allow the error term to be correlated across years for individuals in our panel.

We report our OLS results in Table 6 . We find that workers receive different wages based on race and gender. Also, the $R^{2}$ s contradict Herrnstein and Murray's claim that cognitive ability explains much of wages; for each race-gender group our entire set of regressors explains less than a quarter of the variance in wages. The marginal effect of $g$ is positive 
and statistically significant, and in some cases, some of the other ability measures are also statistically significant. However, the marginal effect of $g$ is of a similar magnitude as some of the other variables; for example, moving someone from the 25 th to 75 th percentile in $\mathrm{g}$ has as much effect on wages as changing one's region of residence.

Table 7 presents a more precise estimate of the percentage of wage variance explained by cognitive ability. For each race-gender group, we estimated the marginal $R^{2}$ of $g$ and AFQT controlling for two different sets of background variables. The first set of background variables consists of indicator variables for year, local and national unemployment rate, and region of residence. The second set includes the first set, plus years of education and potential work experience. Table 7 indicates that if one does not control for human capital measures, $g$ contributes between .199 and .148 to $R^{2}$, and when we control for human capital measures, $g$ contributes .027 and .010 to $R^{2}$. This suggests that the determination of wages is much more complex than Herrnstein and Murray's simple formula of "Prosperity for Those Lucky Enough to be Intelligent".

Thus, for the labor market as a whole, we find strong evidence against Herrnstein and Murray's meritocracy hypothesis. Differences in wages across race and gender cannot be explained by measured ability, and within each race and gender group, measured ability only explains a modest fraction of wage variance. However, meritocracy could still hold within each occupation. We test this hypothesis in the next section. 


\section{Occupation-Specific Wage Equations}

In order to investigate whether the labor market is meritocratic within broad occupational groups, we estimate the following model of wages within occuption:

$$
\begin{aligned}
W_{l, t} & =X_{t} \phi_{l}+\eta_{l, t} \\
E\left(\eta_{l, t} \mid X_{t}\right) & =0
\end{aligned}
$$

where $W_{l, t}$ is the (censored) $\log$ wage in occupation $l$ at date $t$, and where $l=0$ for blue collar and $l=1$ for white collar occupation. As before, we run OLS regressions with Eicker-White standard errors, generalized for panel data, to allow the error term to be correlated across years for individuals in our panel.

The OLS results for blue collar workers are shown in Table 8, and those for white collar workers are shown in Table 10. For both occupations, we reject the hypothesis that individuals of different race or gender are treated equally in the labor market. Workers with the same ability and other characteristics receive different wages depending on race and gender; we reject the null hypothesis of equality of coefficients across race and gender at the $1 \%$ significance level for both groups. The evidence on differences in wage equations is not just a difference in intercepts - we also test whether cognitive ability receives an equal wage return within each occupation regardless of the race and gender of the person in whom the ability is embodied. Specifically, we perform an F test by restricting the coefficients of each of the ten principal components to be equal across race-gender groups. For both blue collar and white collar workers, we decisively reject the null at the $1 \%$ significance level that persons of different race and gender receive an equal wage return for cognitive ability. 
We thus find that intra-occupational racial differences in wages do not disappear once one controls for ability. We find this result in a more general framework than Herrnstein and Murray, since we do not impose the restriction that wage returns to ability are equal across race and gender. Furthermore, even if we do impose this restriction (a restriction that is rejected by the data at the $1 \%$ significance level), the results from the restricted regression contradict Herrnstein and Murray's claim that the black-white wage gap disappears when one controls for gender, age (measured here as potential experience), and cognitive ability. The coefficients on indicator variables for black males and females and Hispanic males and females are statistically significant and negative (the omitted category is white males).

Within race and gender groups, our full set of regressors explains only a modest fraction of the wage variance for either occupation. The $R^{2}$ s of the model are low for both sets of occupations; the entire set of regressors explains between $9 \%$ and $22 \%$ of the variance in wages for blue collar workers and between $22 \%$ and $29 \%$ of the variance in wages for white collar wages. Thus, the regressors explain considerably more of the variance of log wages for white collar than for blue collar workers, with substantial differences in predictive power by race and gender. However, Herrnstein and Murray still overestimate the predictive power of cognitive ability-the model explains less than a third of the variance in wages for any occupation and for any race and gender group.

Table 9 (for blue collar) and Table 11 (for white collar) examines the marginal contribution of $g$ to the fit of the model $\left(R^{2}\right)$ within each occupation. The contribution of $g$ to the fit of the model is very small for blue collar workers: without controlling for human capital measures, the marginal $R^{2}$ of $g$ ranges from .147 to .057 , while controlling for human capital, it ranges from .018 to .003 . It is larger for white collar workers, though it is still modest 
- controlling for human capital measures, the marginal $R^{2}$ for white collar workers ranges from .026 to .009 .

The marginal effect of $g$ is positive and significant for both occupations for all race and gender groups, being considerably larger for white collar workers than blue collar workers. The marginal effects of some of the other cognitive ability measures are statistically significant as well. Still, even for white collar workers, the effect of shifting g one interquartile range has a marginal effect that is comparable to the marginal effect of changing one's region of residence.

Thus we find strong evidence against Herrnstein and Murray's meritocracy hypothesis within each occupation. However, the wages are censored, and thus we have a standard selection problem. We observe the individual's wage in a given occupation only if he or she selected into that occupation. Let $i_{t}=1$ indicate that the individual was observed in occupation 1 (white collar) at date $t$, while $i_{t}=0$ denotes that the individual was observed in occupation 0 (blue collar). We thus identify $E\left(W_{l, t} \mid X_{t}, i_{t}=l\right)=X_{t} \phi_{l}+E\left(\eta_{l, t} \mid X_{t}, i_{t}=l\right)$, so that $\frac{\partial E\left(W_{l, t} \mid X_{t}, i_{t}=l\right)}{\partial X_{t}}=\phi_{l}+\frac{\partial E\left(\eta_{l, t} \mid X_{t}, i_{t}=l\right)}{\partial X_{t}}$ and not $\phi_{l}$. Even though $E\left(\eta_{l, t} \mid X_{t}\right)=0$, it is still the case that, in general, $E\left(\eta_{l, t} \mid X_{t}, i_{t}=l\right) \neq 0$, and $\frac{\partial E\left(W_{l, t} \mid X_{t}, i_{t}=l\right)}{\partial X_{t}} \neq \phi_{l}$. Our result of different returns to ability across race and gender could be due to different underlying returns to ability within the occupation (different $\phi_{l}$ ), different selection into occupations (resulting in different $\left.\frac{\partial E\left(\eta_{l, t} \mid X_{t}, i_{t}=l\right)}{\partial X_{t}}\right)$ or both. This motivates us to correct for selection into occupations, which we do next. 


\section{Simultaneous Estimation of Occupation and Wage}

In this section we enhance the methodology of the previous section by correcting for selfselection into occupations using a simultaneous estimation of occupation choice and wages. This will allow us to examine the determinants of wages and occupation choice, while correcting for self-selection. It will thus allow us to decompose the effect of cognitive ability on wages into the fractions that operate through choice of occupation and through wages given occupation.

Following Cameron and Heckman $(1987,1997)$, we estimate the following version of the Roy model of wages and occupational choice. Individual subscripts are suppressed.

$$
\begin{aligned}
Y_{t} & =Z_{t} \beta+\left(W_{1, t}-W_{0, t}\right) \gamma+\epsilon_{t} \\
W_{l, t} & =X_{t} \phi_{l}+\eta_{l, t} \\
\epsilon_{t} & =\alpha f+v_{t} \\
\eta_{l, t} & =\sigma_{l} f+u_{l, t} \\
i_{t} & =1\left(Y_{t}>0\right)
\end{aligned}
$$

where $Y_{t}$ is the net gain from being in a white collar occupation, i.e. the difference in expected lifetime utility from being in a white collar versus blue collar occupation at date $t$. $W_{l, t}$ is the $\log$ wage for occupation $l$ at date $t$. In our case, $l=0$ for blue collar and $l=1$ for white collar, and $W_{1, t}-W_{0, t}$ is the potential difference in the log wages in white collar versus blue collar sector at date $t$. The indicator variable $i_{t}$ equals one if $Y_{t}>0$, in which case the individual selects into a white collar occupation at date $t$, and equals zero otherwise. The event $i_{t}=1$ thus corresponds to choice of occupation 1 (white collar) while the event 
$i_{t}=0$ corresponds to choice of occupation 0 (blue collar). We assume that $\left(\epsilon_{t}, \eta_{0, t}, \eta_{1, t}\right)$ are independent across persons and are independent within persons conditional on $f . f$ is assumed to be statistically independent of $\left(v_{t}, u_{0, t}, u_{1, t}\right)$. We further assume that $E(f)=0$, $E\left(v_{t}\right)=0$, and $E\left(u_{l, t}\right)=0$ for all $l, t$. We normalize the variance of $v_{t}$ to equal 1 , and define the variance of $u_{1, t}=\sigma_{1}^{2}$ while variance of $u_{0, t}=\sigma_{0}^{2}$.

Instead of assuming joint normality of $\epsilon_{t}, \eta_{0, t}$, and $\eta_{1, t}$, we estimate a nonparametric factor structure model to account for the correlation in an individual's wages over time. $\alpha$ and $\sigma_{l}$ are factor loadings and $f$ is an unobserved factor that does not vary over time; it might be unobserved ability, for example, or motivation. In this model, $f$ is the sole source of dependence between error terms at a given point in time and the sole source of dependence for a given error term over time. We do not know the distribution of the unobserved factor $f$ but we can consistently estimate the distribution using a discrete approximation (see Heckman and Singer, 1984 and Cameron and Heckman, 1987). In this paper, we find that a binary approximation $\left(f=f_{1}\right.$ or $f=f_{2}$ ) fits the data well. We estimate the values of $f$ as well as the probability of each value of $f, P\left(f=f_{1}\right)=P_{1}, P\left(f=f_{2}\right)=P_{2}=1-P_{1}$. The fitted model is thus a binomial discrete factor model. Details on constructing the likelihood are given in Appendix A. The basic approach goes back to Heckman and Singer (1984) and Cameron and Heckman (1987).

In our model, $Z_{t}$ contains variables that affect preferences for a white collar or blue collar occupation. These include test scores, years of education, potential experience, the year the observation is recorded, and indicator variables for whether the respondent's mother or father had a white collar job. $X_{t}$ contains the variables that affect wages, which in our model includes test scores, years of education, potential experience, the year the observation 
is recorded, and indicator variables for the region of residence and local and national unemployment rates. We use region of residence and local and national unemployment rates as exclusion restrictions, which we need for nonparametric identification of our model. These exclusion restrictions are discussed in Appendix A.

Table 12 contains the estimated occupational choice coefficients. The parameters correspond to the net gain equation of being in a white collar versus blue collar occupation. These coefficients represent preferences by the worker for a specific sector of employment. The table indicates that $g$ has a substantial and statistically significant effect on occupational choice. Higher $g$ is associated with a stronger preference for white collar occupations. Other measures of cognitive abilty also have a statistically significant impact on preferences.

Other characteristics besides ability are also important. Predictably, education and the difference in $\log$ wages between the two sectors have statistically significant determinant of choice of occupation. Preferences do vary over race and gender.

In Table 13, we list the percent of accurate predictions by the occupational choice model. Within race-gender groups our overall accuracy ranges from $63 \%$ to $75 \%$. These results indicate that substantial preference heterogeneity remains even after controlling for our full set of regressors.

We are assuming that workers have a free choice of occupation, so that we can interpret $Y_{t}$ as the worker's preference for white versus blue collar occupations. In this formulation, discrimination affects occupation choice only though wages; it does not directly prevent occupation choice. Under this assumption, the finding that things other than ability drive occupation choice is evidence of heterogeneous preferences (and not evidence against a meritocratic labor market). 
An alternative hypothesis is that workers do not have free choice of occupation, and differences in occupation choice across race and gender are caused by discrimination. Our model cannot distinguish between these two hypotheses. Following Poirier (1980), we could augment our model by including a second index determinining whether the worker has the option to work in a white collar occupation, with the index representing the preferences of white collar employers. However, to empirically implement such a model one would need to have additional exclusion restrictions - variables that shift worker preferences but not employer preferences and vice versa. We do not know of any plausible exclusion restrictions for this purpose.

Table 14 (for blue collar) and Table 15 (for white collar) contain the coefficients in the occupation-specific wage regression simultaneously estimated with the model for occupational choice. The wage return to $g$ is positive and statistically significant at the $1 \%$ level with the exception of the blue collar Hispanic females wage equation. However, the wage return to $g$ is even smaller for blue collar workers than without correcting for self-selection. In contrast, the wage return to $g$ is considerably higher for white collar workers with the self-selection correction than without. Thus the previous finding that $g$ has a larger effect on white collar than blue collar wages is even stronger controlling for self-selection. The wage return to certain other measures of ability is again sometimes significant for both blue collar and white collar workers.

However, other factors besides $g$ are statistically significant and of a similar magnitude. For both blue collar and white collar workers, the return to an interquartile shift in $\mathrm{g}$ is of a similar magnitude as a few extra years of education, or a change in region of residence or unemployment rates. Hence, the results of this section are consistent with our previous 
result that persons of different race and gender receive different wage premia for ability.

The coefficient on schooling is significantly larger in the white collar sector than the blue collar sector for each race-gender group. This is consistent with the finding of Keane and Wolpin (1994) who use simulation and interpolation to solve a discrete-choice dynamic programming problem of schooling and occupational choice for NLSY males 1979-88, and find that schooling increased white collar skill $7 \%$ and blue collar skill $2.4 \%$.

Tables $16 \mathrm{~A}$ through $16 \mathrm{E}$ decompose the results of the simultaneous equations model into the effects on wages that cognitive ability has by changing wages within occupation, and by making a change in occupation more likely. Tables $16 \mathrm{~A}$ through $16 \mathrm{E}$ show that each of these two effects is roughly equal for a change in $g$. Only for Hispanic males (Table 16D) and white males (Table 16E) are the two effects dissimilar in magnitude. ${ }^{8}$

The simultaneous estimates are consistent with the results from the previous section: the effect of $g$ on occupational choice and wages is generally statistically significant but modest in magnitude. The effects of a few years of education, the sector of parent's employment, region of residence, and unemployment rates are as large as the wage return to an interquartile shift in $g$.

We note that education may be determined jointly with occupation. Conditioning on education rather than modelling it may lead to systematic bias in the estimated wage equation. We leave a systematic exploration of this possibility for another occasion. 


\section{Conclusion}

We use a simultaneous model of occupational choice and wage determination to examine the claim of Herrnstein and Murray that the U.S. labor market is meritocratic. Our findings are inconsistent with that claim. First, the wage paid to a worker depends on his or her race and gender, even after controlling for cognitive abilty. Indeed, we reject the hypothesis that the wage return to ability is uniform, irrespective of race and gender. ${ }^{9}$ Second, we find that cognitive ability and human capital measures combined explain less than a third of the variance in wages. All of these results create doubt about Herrnstein and Murray's claim that the U.S. labor market is largely governed by meritocratic principles. 


\section{References}

[1] Carroll, John B.. 1993. Human Cognitive Abilities: A Survey of Factor-Analytic Studies. (Cambridge: Cambridge University Press).

[2] Cameron, Steven V. and James J. Heckman. 1997. "The Dynamics of Educational Attainment For Blacks, Whites, and Hispanics." Unpublished manuscript. University of Chicago.

[3] Cameron, Steven V. and James J. Heckman. 1987. "Son of CTM: The DCPA Approach Based on Discrete Factor Structure Models." Unpublished manuscript. University of Chicago.

[4] Cavallo, Alexander, Hazem El-Abbadi, and Randal Heeb. 1997. "The Hidden Gender Restriction: The Need for Proper Controls When Testing for Racial Discrimination." In Intelligence and Success: Is it All in the Genes? Scientists Respond to THE BELL CURVE, edited by Bernie Devlin, Stephen Fienberg, Daniel Resnick, and Kathryn Roeder, pp. 193-214. (New York: Springer Verlag).

[5] Cawley, John, Karen Conneely, James Heckman, and Edward Vytlacil. 1997. "Cognitive Ability, Wages, and Meritocracy." In Intelligence and Success: Is it All in the Genes? Scientists Respond to THE BELL CURVE, edited by Bernie Devlin, Stephen Fienberg, Daniel Resnick, and Kathryn Roeder, pp. 179-192. (New York: Springer Verlag).

[6] Cawley, John, Karen Conneely, James Heckman, and Edward Vytlacil. 1996. "Measuring the Effects of Cognitive Ability." Working Paper No. 5645. Cambridge, MA: National Bureau of Economic Research.

[7] Goldberger, Arthur. 1968. Topics in Regression Analysis, (Macmillan: New York).

[8] Heckman, James. 1995. "Lessons From the Bell Curve." Journal of Political Economy 103(5) (October): 1091-1120.

[9] Heckman, James, and José Scheinkman. 1987. "The Importance of Bundling in a Gorman-Lancaster Model of Earnings." Review of Economic Studies 54(2) (April): 24355.

[10] Heckman, James and Burton Singer. 1984. "A Method for Minimizing the Impact of Distributional Assumption in Econometric Models for Duration Data." Econometrica 52(2) (March): 271-320.

[11] Herrnstein, Richard J. and Charles Murray. 1994. The Bell Curve. (New York: Free Press).

[12] Jensen, Arthur R.. 1987. "The $g$ Beyond Factor Analysis." In The Influence of Cognitive Psychology on Testing and Measurement, (Hillsdale, NJ: L. Erlbaum Associates), edited by R.R. Ronning, J.A. Glover, J.C. Conoley, and J.C. Dewitt. 
[13] Keane, Michael, and Kenneth Wolpin. 1994. "Career Decisions of Young Men." Unpublished manuscript. (September).

[14] Mincer, Jacob. 1974. Schooling, Experience, and Earnings. (New York: Columbia University Press).

[15] Poirier, Dale J.. 1980. "Partial Observability in Bivariate Probit Models." Journal of Econometrics 12: 209-217.

[16] Ree, Malcolm James, James A. Earles, and Mark S. Teachout. 1994. "Predicting Job Performance: Not Much More Than g." Journal of Applied Psychology 79(4): 518-24.

[17] Ree, Malcolm James and James A. Earles. 1991. "Predicting Training Success: Not Much More Than g." Personnel Psychology 44: 321-32. 


\section{A Occupational Choice Model}

Following Cameron and Heckman (1997), we write the following model,

$$
\begin{aligned}
Y_{t} & =Z_{t} \beta+\left(W_{1, t}-W_{0, t}\right) \gamma+\epsilon_{t} \\
W_{l, t} & =X_{t} \phi_{l}+\eta_{l, t} \\
\epsilon_{t} & =\alpha f+v_{t} \\
\eta_{l, t} & =\sigma_{l} f+u_{l, t} \\
i_{t} & =I\left(Y_{t}>0\right)
\end{aligned}
$$

where $Y_{t}$ is the difference in expected lifetime utility from being in a white collar versus blue collar occupation at date $t$, and $W_{l, t}$ is the potential log wages for occupation $l$ at date $t$. In reduced form, we may substitute out for $W_{1, t}$ and $W_{0, t}$ to obtain $Y_{t}=Z_{t} \beta+X_{t}\left(\phi_{1}-\phi_{0}\right) \gamma+$ $\left(\alpha+\left(\sigma_{1}-\sigma_{0}\right) \gamma\right) f+v_{t}+\left(u_{1, t}-u_{0, t}\right) \gamma$. We have $t=1, \ldots, 15$, and $l=0$ for blue collar and $l=1$ for white collar. $\alpha$ is a factor loading and $f$ is an unobserved, non-time covarying factor. The indicator variable $i_{t}$ equals one if $Y_{t}>0$, in which case the individual selects into a white collar occupation at date $t$, and equals zero otherwise.

We assume that $u_{1, t}, u_{0, t}, v_{t}$, and $f$ are each jointly independent of one another for all $t$ and across all persons. We assume that $u_{l, t} \sim N\left(0, \sigma_{u(l)}^{2}\right)$, and $v_{t} \sim N\left(0, \sigma_{v}^{2}\right)$.

\section{A.1 Exclusion Restrictions}

For nonparametric identification of the complete model, we need to impose an exclusion restriction that a variable is included in $X_{t}$ but not in $Z_{t}$, so that the variable does not affect $Y_{t}$ except through $W_{1, t}$ and $W_{0, t}$. In other words, the variable needs to affect wages directly 
but not to directly affect preferences, and thus to affect occupational choice only through its effect on wages. One such exclusion restriction, augmented with additional full support conditions, permits nonparametric identification of the model given the one factor structure.

We impose the exclusion restrictions that region of residence and local and national unemployment rates are included in $X_{t}$ but not $Z_{t}$. Only one of these restrictions must hold for identification.

\section{A.2 Sample Likelihood}

Suppressing individual subscripts and conditioning on $f$, the contribution to likelihood $\mathrm{L}$ of a person is:

$$
\begin{aligned}
\text { Increment to } \mathrm{L} & =\prod_{t} g\left(w_{i_{t}, t}, i_{t} \mid X_{t}, Z_{t}, f\right) \\
& =\prod_{t} g\left(w_{i_{t}, t} \mid X_{t}, f\right) \operatorname{Pr}\left(i_{t} \mid w_{i_{t}, t}, X_{t}, Z_{t}, f\right) \\
\text { where } g\left(w_{i_{t}, t} \mid X_{t}, f\right) & =\frac{1}{\sigma_{u\left(i_{t}\right)}} \phi\left(\frac{W_{i_{t}, t}-X_{t} \phi_{i_{t}}-\sigma_{i_{t}} f}{\sigma_{u\left(i_{t}\right)}}\right) \\
\operatorname{Pr}\left(i_{t}=0 \mid w_{0, t}, X_{t}, Z_{t}, f\right) & =1-\Phi\left(\frac{Z_{t} \beta-\gamma w_{0, t}+\gamma X_{t} \phi_{1}+\left(\gamma \sigma_{1}+\alpha\right) f}{\left(\gamma^{2} \sigma_{u(1)}^{2}+\sigma_{v}^{2}\right)^{1 / 2}}\right) \\
\operatorname{Pr}\left(i_{t}=1 \mid w_{1, t}, X_{t}, Z_{t}, f\right) & =\Phi\left(\frac{Z_{t} \beta+\gamma w_{1, t}-\gamma X_{t} \phi_{0}-\left(\gamma \sigma_{0}-\alpha\right) f}{\left(\gamma^{2} \sigma_{u(0)}^{2}+\sigma_{v}^{2}\right)^{1 / 2}}\right)
\end{aligned}
$$

where we denote the standard normal distribution function by $\Phi$ and the standard normal density by $\phi$.

Then, if we do not condition on $f$ and let $H(f)$ be the distribution of $f$, we have

$$
\text { Increment to } \mathrm{L}=\int \prod_{t} g\left(w_{i_{t}, t}, i_{t} \mid X_{t}, Z_{t}, f\right) d H(f)
$$


We approximate $f$ nonparametrically with a mixing distribution defined on a finite number of support points. As a normalization, we constrain the support points of $f$ to lie in the unit interval. Thus, letting $j$ index the support points for $f$, we approximate the likelihood by:

$$
\text { Increment to } \mathrm{L}=\sum_{j} \prod_{t} g\left(w_{i_{t}, t}, i_{t} \mid X_{t}, Z_{t}, f\right) \operatorname{Pr}\left(f=f_{j}\right)
$$

\section{A.3 Derivation of Predicted Probabilities}

For the table of sample prediction rates (Table 13), we derive the model's estimates of the probability of selecting into a white collar occupation, $P_{t}=\operatorname{Pr}\left(i_{t}=1 \mid X_{t}, Z_{t}\right)$. The reduced form probability (solving out for both $W_{1, t}$ and $W_{0, t}$ ) is

$$
P_{t}=\sum_{j} \Phi\left(\frac{Z_{t} \beta+X_{t} \gamma\left(\phi_{1}-\phi_{0}\right)+\left(\gamma\left(\sigma_{1}-\sigma_{0}\right)+\alpha\right) f}{\left(\gamma^{2}\left(\sigma_{u(0)}^{2}+\sigma_{u(1)}^{2}\right)+\sigma_{v}^{2}\right)^{1 / 2}}\right) \operatorname{Pr}\left(f=f_{j}\right)
$$

\section{A.4 Derivation of $R^{2}$}

In Tables 14 and 15, we report the $R^{2}$ s for the wage equations from our model. We derive $R^{2}$ as follows. Let $W_{l}$ be a column vector of the observed wages in sector $l$. We define our $R^{2}$ for sector $l$ as:

$$
R^{2}=1-\frac{\left(W_{l}-E\left(W_{l} \mid X, Z, l\right)\right)^{\prime}\left(W_{l}-E\left(W_{l} \mid X, Z, l\right)\right)}{\left(W_{l}-E\left(W_{l} \mid l\right)\right)^{\prime}\left(W_{l}-E\left(W_{l} \mid l\right)\right)}
$$

where $E\left(W_{l} \mid X, Z, l\right)$ is a column vector of the expected wages for those observations where wages in sector $l$ are observed. We estimate $E\left(W_{l} \mid l\right)$ by the sample mean of wages in sector l. In order to estimate $E\left(W_{l} \mid X, Z, l\right)$, we first derive the expression for $E\left(W_{1, t} \mid X_{t}, Z_{t}, i_{t}=1\right)$ 
and then the expression for $E\left(W_{0, t} \mid X_{t}, Z_{t}, i_{t}=0\right)$. We have that

$$
\begin{aligned}
& E\left(W_{1, t} \mid X_{t}, Z_{t}, i_{t}=1\right) \\
= & X_{t} \phi_{1}+E\left(\eta_{1, t} \mid X_{t}, Z_{t}, i_{t}=1\right) \\
= & X_{t} \phi_{1}+ \\
& E\left(\eta_{1, t} \mid X_{t}, Z_{t}, Z_{t} \beta+\left(W_{1, t}-W_{0, t}\right) \gamma+\epsilon_{t}>0\right) .
\end{aligned}
$$

Let $C=Z_{t} \beta+X_{t}\left(\phi_{1}-\phi_{0}\right) \gamma$. Plugging in the reduced forms for wages, we obtain

$$
\begin{aligned}
& E\left(W_{1, t} \mid X_{t}, Z_{t}, i_{t}=1\right) \\
= & X_{t} \phi_{1}+E\left(\eta_{1, t} \mid X_{t}, Z_{t}, Z_{t} \beta+X_{t}\left(\phi_{1}-\phi_{0}\right) \gamma+\left(\eta_{1, t}-\eta_{0, t}\right) \gamma+\epsilon_{t}>0\right) \\
= & X_{t} \phi_{1}+E\left(\eta_{1, t} \mid X_{t}, Z_{t}, C+\left(u_{1, t}-u_{0, t}+\left(\sigma_{1}-\sigma_{0}\right) f\right) \gamma+\epsilon_{t}>0\right) \\
= & X_{t} \phi_{1} \\
& +E\left(u_{1, t} \mid X_{t}, Z_{t},\left(u_{1, t}-u_{0, t}+\left(\sigma_{1}-\sigma_{0}\right) f\right) \gamma+\epsilon_{t}>-C\right) \\
& +\sigma_{1} E\left(f \mid X_{t}, Z_{t},\left(u_{1, t}-u_{0, t}+\left(\sigma_{1}-\sigma_{0}\right) f\right) \gamma+\epsilon_{t}>-C\right) .
\end{aligned}
$$

Let $\rho_{t}=\left(u_{1, t}-u_{0, t}\right) \gamma+v_{t}$. Note that $\rho_{t} \sim N\left(0, \sigma_{\rho}^{2}\right)$, where $\sigma_{\rho}^{2}=\gamma^{2}\left(\sigma_{u(1)}^{2}+\sigma_{u(0)}^{2}\right)+\sigma_{v}^{2}$. 
Also note that $\operatorname{cov}\left(u_{1, t}, \rho_{t}\right)=\gamma \sigma_{u(1)}^{2}$. We have that the second term of (11) is:

$$
\begin{aligned}
& E\left(u_{1, t} \mid X_{t}, Z_{t},\left(u_{1, t}-u_{0, t}+\left(\sigma_{1}-\sigma_{0}\right) f\right) \gamma+\epsilon_{t}>-C\right) \\
= & E\left(u_{1, t} \mid X_{t}, Z_{t}, \rho_{t}>-\left(\alpha+\left(\sigma_{1}-\sigma_{0}\right) \gamma\right) f-C\right) \\
= & E_{f}\left[E\left(u_{1, t} \mid X_{t}, Z_{t}, \frac{\rho_{t}}{\sigma_{\rho}}>\frac{-\left(\alpha+\left(\sigma_{1}-\sigma_{0}\right) \gamma\right) f-C}{\sigma_{\rho}}, f\right)\right] \\
= & \frac{\operatorname{cov}\left(u_{1, t}, \rho_{t}\right)}{\sqrt{\operatorname{var}\left(\rho_{t}\right)}} E_{f}\left[\phi\left(\frac{-\left(\alpha+\left(\sigma_{1}-\sigma_{0}\right) \gamma\right) f-C}{\sigma_{\rho}}\right) /\left(1-\Phi\left(\frac{-\left(\alpha+\left(\sigma_{1}-\sigma_{0}\right) \gamma\right) f-C}{\sigma_{\rho}}\right)\right)\right] \\
= & \frac{\gamma \sigma_{u(1)}^{2}}{\sigma_{\rho}}\left(\sum_{j} \operatorname{Pr}\left(f=f_{j}\right) \times\right. \\
& {\left.\left[\phi\left(\frac{\left(\alpha+\left(\sigma_{1}-\sigma_{0}\right) \gamma\right) f_{2}+C}{\sigma_{\rho}}\right) / \Phi\left(\frac{\left(\alpha+\left(\sigma_{1}-\sigma_{0}\right) \gamma\right) f_{j}+C}{\sigma_{\rho}}\right)\right]\right) . }
\end{aligned}
$$

To analyze the third term of (11), we specialize to the case where $f$ has two support points located at zero and one. Letting $C^{*}=\frac{\alpha+\left(\sigma_{1}-\sigma_{0}\right) \gamma+C}{\sigma_{\rho}}$, we have by Bayes' theorem that

$$
\begin{aligned}
& E\left(f \mid X_{t}, Z_{t},\left(u_{1, t}-u_{0, t}+\left(\sigma_{1}-\sigma_{0}\right) f\right) \gamma+\epsilon_{t}>-C\right) \\
= & \operatorname{Pr}\left(f=1 \mid X_{t}, Z_{t},\left(\alpha+\left(\sigma_{1}-\sigma_{0}\right) \gamma\right) f+\rho_{t}>-C\right) \\
= & \frac{\operatorname{Pr}\left(f=1,\left(\alpha+\left(\sigma_{1}-\sigma_{0}\right) \gamma\right) f+\rho_{t}>-C \mid X_{t}, Z_{t}\right)}{\operatorname{Pr}\left(\left(\alpha+\left(\sigma_{1}-\sigma_{0}\right) \gamma\right) f+\rho_{t}>-C \mid X_{t}, Z_{t}\right)} \\
= & \frac{\operatorname{Pr}\left(f=1, \alpha+\left(\sigma_{1}-\sigma_{0}\right) \gamma+\rho_{t}>-C \mid X_{t}, Z_{t}\right)}{P_{t}} \\
= & \frac{\operatorname{Pr}(f=1) \Phi\left(C^{*}\right)}{P_{t}}
\end{aligned}
$$

where $P_{t}=\operatorname{Pr}\left(i_{t}=1 \mid X_{t}, Z_{t}\right)$ is specified in equation (8). Combining the results of (11), (12), and (13), we have that

$$
\begin{aligned}
& E\left(W_{1, t} \mid X_{t}, Z_{t}, i_{t}=1\right) \\
= & X_{t} \phi_{1}+\frac{\gamma \sigma_{u(1)}^{2}}{\sigma_{\rho}}\left[\operatorname{Pr}(f=0)\left[\phi\left(\frac{C}{\sigma_{\rho}}\right) / \Phi\left(\frac{C}{\sigma_{\rho}}\right)\right]\right. \\
& \left.+\operatorname{Pr}(f=1)\left[\phi\left(C^{*}\right) / \Phi\left(C^{*}\right)\right]\right]+\sigma_{1} \frac{\operatorname{Pr}(f=1) \Phi\left(C^{*}\right)}{P_{t}} .
\end{aligned}
$$


We now have all terms for equation (10), and can thus compute the $R^{2}$ for our white collar wage equation. For the blue collar wage equation, we follow the parallel arguement and obtain

$$
\begin{aligned}
& E\left(W_{0, t} \mid X_{t}, Z_{t}, i_{t}=0\right) \\
= & X_{t} \phi_{0}+\frac{\gamma \sigma_{u(0)}^{2}}{\sigma_{\rho}}\left[\operatorname{Pr}(f=0)\left[\phi\left(\frac{C}{\sigma_{\rho}}\right) /\left(1-\Phi\left(\frac{C}{\sigma_{\rho}}\right)\right)\right]\right. \\
& \left.+\operatorname{Pr}(f=1)\left[\phi\left(C^{*}\right) /\left(1-\Phi\left(C^{*}\right)\right)\right]\right]+\sigma_{0} \frac{\operatorname{Pr}(f=1)\left(1-\Phi\left(C^{*}\right)\right)}{1-P_{t}}
\end{aligned}
$$

\section{A.5 Derivations for Decompositions}

In Tables 16A-16F, we report the results of decomposing the effect of covariates on wages into the effect through wages given occupational choice and the effect through occupation choice. We derive the formula for this decomposition as follows. Let $W_{t}$ be the observed wages, so that:

$$
W_{t}=W_{0, t}+i_{t}\left(W_{1, t}-W_{0, t}\right)
$$

We now wish to take the derivative with respect to a particular variable $X_{t}^{k}$, which is presumed to be the $k$ th element of both $Z_{t}$ and $X_{t}$. While changing the covariate $X_{t}^{k}$, we are assuming that each individual's values of $\epsilon_{t}$ and $\eta_{l, t}$ remain fixed (this follows on average

from the assumed independence). Thus, for example, if $\frac{\partial P_{t}}{\partial X_{t}^{k}}>0$, the expected effect of an increase in $X_{t}^{k}$ is both an expected effect on wages given occupation, and an expected effect due to some individuals switching from blue collar into white collar occupations as a result of the change in $X_{t}^{k}$. We may write the expected wage as:

$$
E\left(W_{t} \mid X_{t}, Z_{t}\right)=E\left(W_{0, t} \mid X_{t}\right)+P_{t} \times\left(E\left(W_{1, t}-W_{0, t} \mid X_{t}, Z_{t}, i_{t}=1\right)\right)
$$


Differentiating with respect to $X_{t}$, we obtain

$$
\begin{aligned}
\frac{\partial E\left(W_{t} \mid X_{t}, Z_{t}\right)}{\partial X_{t}^{k}}= & \phi_{0}^{k}+\left[P_{t} \times\left(\frac{\partial E\left(W_{1, t}-W_{0, t} \mid X_{t}, Z_{t}, i_{t}=1\right)}{\partial X_{t}^{k}}\right)\right] \\
& +\left[\frac{\partial P_{t}}{\partial X_{t}^{k}} \times\left(E\left(W_{1, t}-W_{0, t} \mid X_{t}, Z_{t}, i_{t}=1\right)\right)\right]
\end{aligned}
$$

We have that

$$
\begin{aligned}
\frac{\partial P_{t}}{\partial X_{t}^{k}} & =\frac{\partial \operatorname{Pr}\left(i_{t}=1 \mid X_{t}, Z_{t}\right)}{\partial X_{t}^{k}} \\
& =\sum_{j} \phi\left(\frac{C+\left(\gamma\left(\sigma_{1}-\sigma_{0}\right)+\alpha\right) f}{\sigma_{\rho}}\right) \times \frac{\beta^{k}+\gamma\left(\phi_{1}^{k}-\phi_{0}^{k}\right)}{\sigma_{\rho}} \operatorname{Pr}\left(f=f_{j}\right) .
\end{aligned}
$$

$E\left(W_{1, t} \mid X_{t}, Z_{t}, i_{t}=1\right)$ was derived above, and is given by equation (14). Following a parallel arguement for $E\left(W_{0, t} \mid X_{t}, Z_{t}, i_{t}=1\right)$, we obtain

$$
\begin{aligned}
& E\left(W_{0, t} \mid X_{t}, Z_{t}, i_{t}=1\right) \\
= & X_{t} \phi_{0}-\frac{\gamma \sigma_{u(0)}^{2}}{\sigma_{\rho}}\left[\operatorname{Pr}(f=0)\left[\phi\left(\frac{C}{\sigma_{\rho}}\right) / \Phi\left(\frac{C}{\sigma_{\rho}}\right)\right]\right. \\
& \left.+\operatorname{Pr}(f=1)\left[\phi\left(C^{*}\right) / \Phi\left(C^{*}\right)\right]\right]+\sigma_{0} \frac{\operatorname{Pr}(f=1) \Phi\left(C^{*}\right)}{P_{t}}
\end{aligned}
$$

Combining the results of (14) and (20), we have that

$$
\begin{aligned}
& E\left(W_{1, t}-W_{0, t} \mid X_{t}, Z_{t}, i_{t}=1\right) \\
= & X_{t}\left(\phi_{1}-\phi_{0}\right)+\frac{\gamma\left(\sigma_{u(1)}^{2}+\sigma_{u(0)}^{2}\right)}{\sigma_{\rho}}\left[\operatorname{Pr}(f=0)\left[\phi\left(\frac{C}{\sigma_{\rho}}\right) / \Phi\left(\frac{C}{\sigma_{\rho}}\right)\right]\right. \\
& \left.+\operatorname{Pr}(f=1)\left[\phi\left(C^{*}\right) / \Phi\left(C^{*}\right)\right]\right]+\left(\sigma_{1}-\sigma_{0}\right) \frac{\operatorname{Pr}(f=1) \Phi\left(C^{*}\right)}{P_{t}}
\end{aligned}
$$


To obtain $\frac{\partial E\left(W_{1, t}-W_{0, t} \mid X_{t}, Z_{t, i_{t}}=1\right)}{\partial X_{t}^{k}}$, we take the derivative of $(21)$ with respect to $X_{t}^{k}$ :

$$
\begin{aligned}
& \quad \frac{\partial E\left(W_{1, t}-W_{0, t} \mid X_{t}, Z_{t}, i_{t}=1\right)}{\partial X_{t}^{k}} \\
& =\left(\phi_{1}^{k}-\phi_{0}^{k}\right)-\frac{\gamma\left(\sigma_{u(1)}^{2}+\sigma_{u(0)}^{2}\right)}{\sigma_{\rho}} \frac{\beta^{k}+\left(\phi_{1}^{k}-\phi_{0}^{k}\right) \gamma}{\sigma_{\rho}} \\
& \quad \times\left(\operatorname{Pr}(f=0) \phi\left(\frac{C}{\sigma_{\rho}}\right)\left[\frac{\frac{C}{\sigma_{\rho}} \Phi\left(\frac{C}{\sigma_{\rho}}\right)+\phi\left(\frac{C}{\sigma_{\rho}}\right)}{\left[\Phi\left(\frac{C}{\sigma_{\rho}}\right)\right]^{2}}\right]\right. \\
& \left.+\operatorname{Pr}(f=1) \phi\left(C^{*}\right)\left[\frac{C^{*} \Phi\left(C^{*}\right)+\phi\left(C^{*}\right)}{\Phi\left(C^{*}\right)^{2}}\right]\right) \\
& +\left(\sigma_{1}-\sigma_{0}\right) \operatorname{Pr}(f=1) \times\left[\frac{P_{t} \phi\left(C^{*}\right) \frac{\beta^{k}+\left(\phi_{1}^{k}-\phi_{0}^{k}\right) \gamma}{\sigma_{\rho}}-\Phi\left(C^{*}\right) \frac{\partial P_{t}}{\partial X_{t}^{k}}}{P_{t}^{2}}\right]
\end{aligned}
$$

Combining the results from equations (19), (21) and (22) we have now derived all terms of equation (18). 


\section{Notes}

${ }^{1}$ As noted by Goldberger (1968), the size of a regression coefficient or a standardized regression coefficient is not a useful guide to the contribution of the variable to overall fit unless the regressors are mutually orthogonal. The ten measures of cognitive ability that we use in this paper are mutually orthogonal.

${ }^{2}$ The ASVAB weights for all ten principal components are available upon request from the authors. These weights can be used to derive the coefficients on the original ten ASVAB scores implied by the coefficients on the principal components in any of our regressions.

${ }^{3}$ Our six race and gender groups are white males, white females, Hispanic males, Hispanic females, black males and black females.

${ }^{4}$ See Cawley et al., 1996, for a more detailed discussion of the principal components and their interpretation.

${ }^{5}$ The reason we use such broad occupational categories is that the semiparametric estimation of our simultaneous model of occupation and wages is very data intensive and that we are fitting the same model to each race-gender group. The model becomes unstable for some race-gender groups when we attempt to estimate it with more narrowly defined occupational categories. The primary reason for this instability is that the NLSY does not have a sufficient number of observations in each occupational category for some race-gender groups. We believe estimating the model with more narrowly defined occupational categories to be feasible and promising if fewer race-gender groups are considered; in particular, we believe an examination of sales and clerical vs management and professional occupations for white men and white women to be an important avenue for future research.

${ }^{6}$ Our analysis here is substantially different from that of Herrnstein and Murray. They regressed wages on age, IQ, and gender separately by race, and measured discrimination by comparing the wages of different races at the "average" levels of these characteristics. Their wage equation is misspecified and their measure of discrimination is problematic. Cavallo et al. (1997) contains a more detailed discussion of the problems with Herrnstein and Murray's empirical methodology and the sensitivity of their results to their specification of the wage equation and to their measure of discrimination.

${ }^{7}$ Herrnstein and Murray often include a one-dimensional measure of socio-economic background, SES, in their regression analysis. They do this in an attempt to differentiate between the influences of inborn "ability" versus "environment." We believe the use of SES to distinguish between "ability" and "environment" to be highly questionable - see the discussion in Heckman (1995). We are not concerned here with the "nature versus nurture" debate, and thus do not include SES in our analysis. However, in results not shown here, we find that including SES in our analysis reduces the coefficients on cognitive ability even further.

${ }^{8}$ The derivations for our simultaneous equations model appear in the appendix.

${ }^{9}$ Our finding that ability does not earn a constant wage return in the labor market is not 
conclusive evidence of discrimination. One other possible explanation is that abilities tend to be bundled, and cannot be separately priced out by the labor market (See Heckman and Scheinkman (1987)). Segmentation within the labor market could also create the patterns we find. 


\begin{tabular}{|l|l|l||}
\hline \hline Table 1: The Armed Services Vocational Aptitude Battery \\
\hline \hline Subtest & Minutes & Description (A subtest of ASVAB measuring...) \\
\hline \hline General Science & 11 & Knowledge of the physical and biological sciences. \\
\hline Arithmetic Reasoning & 36 & Ability to solve arithmetic word problems. \\
\hline Word Knowledge & 11 & $\begin{array}{l}\text { Ability to select the correct meaning of words } \\
\text { presented in context and to identify the best } \\
\text { synonym for a given word. }\end{array}$ \\
\hline Paragraph Comprehension & 13 & Ability to obtain information from written passages. \\
\hline Numerical Operations & 3 & $\begin{array}{l}\text { Ability to perform arithmetic computations } \\
\text { (speeded). }\end{array}$ \\
\hline Coding Speed & 7 & $\begin{array}{l}\text { Ability to use a key in assigning code numbers to } \\
\text { words (speeded). }\end{array}$ \\
\hline Auto and Shop Information & 11 & $\begin{array}{l}\text { Knowledge of automobiles, tools, and shop } \\
\text { terminology and practices. }\end{array}$ \\
\hline Mathematics Knowledge & 24 & Knowledge of high school mathematics principles. \\
\hline Mechanical Comprehension & 19 & $\begin{array}{l}\text { Knowledge of mechanical and physical principles } \\
\text { and ability to visualize how illustrated objects work. }\end{array}$ \\
\hline Electronics Information & 9 & Knowledge of electricity and electronics. \\
\hline \hline ASVAB Testing Time & 144 & \\
\hline
\end{tabular}




\begin{tabular}{||l|c|c|c|c|c|c||}
\hline \hline Table 2: Construction of "g" by Race and Gender \\
\hline ASVAB Subtest & $\begin{array}{c}\text { Black } \\
\text { Females }\end{array}$ & $\begin{array}{c}\text { Black } \\
\text { Males }\end{array}$ & $\begin{array}{c}\text { Hispanic } \\
\text { Females }\end{array}$ & $\begin{array}{c}\text { Hispanic } \\
\text { Males }\end{array}$ & $\begin{array}{c}\text { White } \\
\text { Females }\end{array}$ & $\begin{array}{c}\text { White } \\
\text { Males }\end{array}$ \\
\hline General Science & 0.351 & 0.338 & 0.340 & 0.336 & 0.343 & 0.344 \\
\hline Arithmetic Reasoning & 0.325 & 0.319 & 0.331 & 0.325 & 0.356 & 0.341 \\
\hline Word Knowledge & 0.375 & 0.352 & 0.346 & 0.342 & 0.354 & 0.347 \\
\hline Paragraph Comprehension & 0.360 & 0.332 & 0.339 & 0.329 & 0.331 & 0.331 \\
\hline Numerical Operations & 0.311 & 0.292 & 0.287 & 0.287 & 0.277 & 0.285 \\
\hline Coding Speed & 0.281 & 0.278 & 0.274 & 0.286 & 0.248 & 0.270 \\
\hline Auto + Shop Information & 0.257 & 0.302 & 0.304 & 0.301 & 0.272 & 0.264 \\
\hline Math Knowledge & 0.343 & 0.314 & 0.319 & 0.309 & 0.338 & 0.324 \\
\hline Mechanical Comprehension & 0.243 & 0.304 & 0.302 & 0.316 & 0.311 & 0.315 \\
\hline Electronic Information & 0.289 & 0.324 & 0.312 & 0.327 & 0.311 & 0.328 \\
\hline \hline
\end{tabular}

\begin{tabular}{|c|c|c|c|c|c|c|}
\hline $\begin{array}{l}\text { Principal } \\
\text { Component }\end{array}$ & $\begin{array}{c}\text { Black } \\
\text { Females }\end{array}$ & $\begin{array}{l}\text { Black } \\
\text { Males }\end{array}$ & $\begin{array}{l}\text { Hispanic } \\
\text { Females }\end{array}$ & $\begin{array}{c}\text { Hispanic } \\
\text { Males }\end{array}$ & $\begin{array}{c}\text { White } \\
\text { Females }\end{array}$ & $\begin{array}{l}\text { White } \\
\text { Males }\end{array}$ \\
\hline First (g) & 0.552 & 0.637 & 0.650 & 0.706 & 0.579 & 0.639 \\
\hline Second & 0.096 & 0.085 & 0.079 & 0.081 & 0.108 & 0.114 \\
\hline Third & 0.070 & 0.060 & 0.054 & 0.052 & 0.068 & 0.059 \\
\hline Fourth & 0.063 & 0.050 & 0.043 & 0.037 & 0.058 & 0.046 \\
\hline Fifth & 0.060 & 0.035 & 0.039 & 0.028 & 0.043 & 0.031 \\
\hline Sixth & 0.047 & 0.032 & 0.036 & 0.023 & 0.039 & 0.030 \\
\hline Seventh & 0.033 & 0.030 & 0.031 & 0.021 & 0.033 & 0.025 \\
\hline Eighth & 0.031 & 0.028 & 0.026 & 0.020 & 0.031 & 0.023 \\
\hline Ninth & 0.028 & 0.026 & 0.024 & 0.017 & 0.022 & 0.017 \\
\hline Tenth & 0.019 & 0.016 & 0.017 & 0.014 & 0.018 & 0.016 \\
\hline
\end{tabular}


TABLE 4

Mean Test Scores By Job Category at Age 30

Test Scores Standardized to Mean 0, Inter-Quartile Range=1 for Each Race,Gender Group

Job Categories: White Collar vs Blue Collar

Standard Errors in Parentheses

\begin{tabular}{|c|c|c|c|c|c|c|c|c|c|c|c|}
\hline \multicolumn{12}{|c|}{ Principal Components } \\
\hline & No. Obs & 1st P.C. & 2nd P.C. & 3rd P.C. & 4rth P.C. & 5th P.C. & 6th P.C. & 7 th P.C. & 8th P.C. & 9th P.C. & loth P.C \\
\hline \multirow[t]{2}{*}{ Black Fem, White Collar } & 511 & 0.32 & -.09 & 0.04 & 0.02 & -.01 & -.06 & 0.05 & 0.01 & 0.05 & -.00 \\
\hline & & $(0.03)$ & $(0.03)$ & $(0.03)$ & $(0.03)$ & $(0.04)$ & $(0.03)$ & $(0.03)$ & $(0.03)$ & $(0.03)$ & $(0.03)$ \\
\hline \multirow[t]{2}{*}{ Black Fern, Blue Collar } & 371 & -.22 & 0.02 & .04 & 0.08 & -.01 & 0.04 & 0.03 & 0.01 & -.09 &. .00 \\
\hline & & $(0.03)$ & $(0.03)$ & $(0.04)$ & $(0.03)$ & $(0.04)$ & $(0.04)$ & $(0.04)$ & $(0.04)$ & $(0.04)$ & $(0.04)$ \\
\hline \multirow[t]{2}{*}{ Difference: } & 882 & 0.54 & -.11 & 0.09 &. .05 & 0.00 & -.10 & 0.02 & -.00 & 0.14 & -.00 \\
\hline & & $(0.04)$ & $(0.05)$ & $(0.05)$ & $(0.05)$ & $(0.05)$ & $(0.05)$ & $(0.05)$ & $(0.05)$ & $(0.05)$ & $(0.05)$ \\
\hline \multirow[t]{2}{*}{ Black Male, White Collar } & $28 !$ & 0.47 & 0.17 & -.11 & 0.04 & -.01 & -.01 & 0.02 & -.05 & 0.03 & .01 \\
\hline & & $(0.04)$ & $(0.05)$ & $(0.05)$ & $(0.05)$ & $(0.05)$ & $(0.05)$ & $(0.05)$ & $(0.04)$ & $(0.05)$ & $(0.04)$ \\
\hline \multirow[t]{2}{*}{ Black Male, Blue Collar } & 664 & -.16 & -.09 & 0.06 & 0.05 & 0.06 & -.00 & -.01 & 0.03 & .04 & 0.04 \\
\hline & & $(0.02)$ & $(0.03)$ & $(0.03)$ & $(0.03)$ & $(0.03)$ & $(0.03)$ & $(0.03)$ & $(0.03)$ & $(0.03)$ & $(0.03)$ \\
\hline \multirow[t]{2}{*}{ Difference: } & 945 & 0.62 & 0.25 & -.17 & -.01 &. .07 & -.00 & 0.03 & -.08 & 0.07 & -.05 \\
\hline & & $(0.05)$ & $(0.06)$ & $(0.06)$ & $(0.05)$ & $(0.05)$ & $(0.05)$ & $(0.06)$ & $(0.05)$ & $(0.06)$ & $(0.05)$ \\
\hline \multirow[t]{2}{*}{ Hisp Fem, White Collar } & 353 & 0.33 & 0.08 & 0.02 & -.02 & 0.03 & -.04 & -.05 & .08 & 0.01 & -.04 \\
\hline & & $(0.04)$ & $(0.04)$ & $(0.04)$ & $(0.04)$ & $(0.04)$ & $(0.04)$ & $(0.04)$ & $(0.04)$ & $(0.04)$ & $(0.04)$ \\
\hline \multirow[t]{2}{*}{ Hisp Fem, Blue Collar } & 185 & -.15 & -.05 & -.04 & 0.10 & -.06 & 0.03 & 0.09 & 0.08 &. .02 & 0.15 \\
\hline & & $(0.06)$ & $(0.05)$ & $(0.05)$ & $(0.05)$ & $(0.06)$ & $(0.05)$ & $(0.06)$ & $(0.06)$ & $(0.05)$ & $(0.06)$ \\
\hline \multirow[t]{2}{*}{ Difference: } & 538 & 0.48 & 0.13 & 0.06 & -.12 & 0.09 & -.08 & -.14 & -.16 & 0.03 & -.19 \\
\hline & & $(0.07)$ & $(0.06)$ & $(0.07)$ & $(0.06)$ & $(0.07)$ & $(0.07)$ & $(0.07)$ & $(0.07)$ & $(0.07)$ & $(0.07)$ \\
\hline \multirow[t]{2}{*}{ Hisp Male, White Callar } & 216 & 0.32 & 0.17 & -.11 & -.09 & -.10 &. .06 & 0.06 & 0.01 & 0.02 & 0.04 \\
\hline & & $(0.04)$ & $(0.05)$ & $(0.05)$ & $(0.05)$ & $(0.06)$ & $(0.05)$ & $(0.05)$ & $(0.05)$ & $(0.05)$ & $(0.05)$ \\
\hline \multirow[t]{2}{*}{ Hisp Male. Blue Collar } & 411 & -.13 & -.10 & 0.11 & 0.10 & 0.07 & 0.02 & 0.03 & -.05 & 0.04 & 0.01 \\
\hline & & $(0.03)$ & $(0.04)$ & $(0.03)$ & $(0.04)$ & $(0.04)$ & $(0.04)$ & $(0.04)$ & $(0.04)$ & $(0.04)$ & $(0.04)$ \\
\hline \multirow[t]{2}{*}{ Difference: } & 627 & 0.44 & 0.27 & -.22 & -.18 & -.17 & -.08 & 0.03 & 0.07 & -.02 & 0.03 \\
\hline & & $(0.05)$ & $(0.07)$ & $(0.06)$ & $(0.06)$ & $(0.07)$ & $(0.06)$ & $(0.06)$ & $(0.06)$ & $(0.06)$ & $(0.06)$ \\
\hline \multirow[t]{2}{*}{ White Fem, White Collar } & 1349 & 0.20 & 0.06 & 0.01 & -.01 & 0.01 & 0.01 & -.01 & 0.01 & -.03 & -.01 \\
\hline & & $(0.02)$ & $(0.02)$ & $(0.02)$ & $(0.02)$ & $(0.02)$ & $(0.02)$ & $(0.02)$ & $(0.02)$ & $(0.02)$ & $(0.02)$ \\
\hline \multirow[t]{2}{*}{ White Fem, Blue Collar } & 586 & -.30 & -.17 & 0.15 & 0.02 & 0.06 & 0.03 & .01 & 0.02 & -.01 & -.06 \\
\hline & & $(0.03)$ & $(0.03)$ & $(0.03)$ & $(0.03)$ & $(0.03)$ & $(0.03)$ & $(0.03)$ & $(0.03)$ & $(0.03)$ & $(0.03)$ \\
\hline \multirow[t]{2}{*}{ Difference: } & 1935 & 0.50 & 0.23 & -.14 & -.03 & -.05 & -.03 & 0.00 & -.01 & -.01 & 0.04 \\
\hline & & $(0.03)$ & $(0.03)$ & $(0.04)$ & $(0.04)$ & $(0.04)$ & $(0.04)$ & $(0.04)$ & $(0.04)$ & $(0.04)$ & $(0.04)$ \\
\hline \multirow[t]{2}{*}{ White Male, White Collar } & 889 & 0.31 & 0.19 & -.10 & 0.01 & -.03 & .07 & -.00 & 0.01 & 0.01 & 0.04 \\
\hline & & $(0.02)$ & $(0.02)$ & $(0.02)$ & $(0.02)$ & $(0.03)$ & $(0.02)$ & $(0.03)$ & $(0.02)$ & $(0.02)$ & $(0.02)$ \\
\hline \multirow[t]{2}{*}{ White Male, Blue Collar } & 1089 & -.21 & -.19 & 0.14 & -.00 & 0.05 & 0.04 & 0.04 & 0.02 & 0.03 & -.03 \\
\hline & & $(0.02)$ & $(0.02)$ & $(0.02)$ & $(0.02)$ & $(0.02)$ & $(0.02)$ & $(0.02)$ & $(0.02)$ & $(0.03)$ & $(0.02)$ \\
\hline \multirow[t]{2}{*}{ Difference: } & 1978 & 0.53 & 0.38 & -.24 & 0.01 & -.09 & -.11 & -.05 & -.00 & -.02 & 0.07 \\
\hline & & $(0.03)$ & $(0.03)$ & $(0.03)$ & $(0.03)$ & $(0.04)$ & $(0.03)$ & $(0.03)$ & $(0.03)$ & $(0.03)$ & $(0.03)$ \\
\hline
\end{tabular}

1. Table crealed on 06MAR97

2. 1st P.C. through 10h P.C. refer to the first through tenth group specific prinkipal components. They have been adjusted for age when testod 
TABLE 5

Mean Test Scores By Job Category at Age 30

Test Scores Standardized to Mean 0, Inter-Quartile Range=1 for Entire Population Job Categories: White Collar vs Blue Collar

Standard Errors in Parentheses

\section{ASVAB Scores}

\begin{tabular}{|c|c|c|c|c|c|c|c|c|c|c|c|}
\hline & No. Obs & Gen Sci & Num Op & Auto Shop & Mech Comp & Elec Info & Arith Reas & Coding Sp & Math Know & Para Comp & Word Know \\
\hline \multirow{2}{*}{ Black Fem. White Collar } & 511 & -.40 & -.15 & -.60 & -.57 & -.54 & -.41 & -.08 &. .23 & -.17 & -.27 \\
\hline & & $(0.02)$ & $(0.03)$ & $(0.01)$ & $(0.02)$ & $(0.02)$ & $(0.02)$ & $(0.03)$ & $(0.02)$ & $(0.02)$ & $(0.02)$ \\
\hline \multirow[t]{2}{*}{ Black Fem, Blue Collar } & 371 & -.72 & -.56 &. .71 & -.73 & -.70 & -.64 &. .52 & -.58 &. .57 & .66 \\
\hline & & $(0.02)$ & $(0.03)$ & $(0.02)$ & $(0.02)$ & $(0.02)$ & $(0.02)$ & $(0.04)$ & $(0.02)$ & $(0.03)$ & $(0.03)$ \\
\hline \multirow[t]{2}{*}{ Difference: } & 882 & 0.32 & 0.41 & 0.11 & 0.16 & 0.16 & 0.22 & 0.43 & 0.34 & 0.39 & 0.39 \\
\hline & & $(0.03)$ & $(0.04\}$ & $(0.02)$ & $(0.02)$ & $(0.03)$ & $(0.03)$ & $(0.05)$ & $(0.03)$ & $(0.04)$ & $(0.03)$ \\
\hline \multirow[t]{2}{*}{ Black Male, White Collar } & 281 & -.21 & -.18 & -.19 & -.21 & -.15 & -.20 & -.31 & -.10 & -.19 & -.21 \\
\hline & & $(0.04)$ & $(0.04)$ & $(0.03)$ & $(0.04)$ & $(0.04)$ & $(0.03)$ & $(0.04)$ & $(0.04)$ & $(0.03)$ & $(0.03)$ \\
\hline \multirow[t]{2}{*}{ Black Male, Blue Collar } & 664 & -.63 & -.71 & -.42 & -.53 & -.47 & -.57 & -.81 &. .53 & -.65 & -.69 \\
\hline & & $(0.02)$ & $(0.03)$ & $(0.02)$ & $(0.02)$ & $(0.02)$ & $(0.01)$ & $(0.02)$ & $(0.01)$ & $(0.02)$ & $(0.02)$ \\
\hline \multirow[t]{2}{*}{ Difference: } & 945 & 0.42 & 0.54 & 0.23 & 0.32 & 0.32 & 0.36 & 0.49 & 0.43 & 0.46 & 0.48 \\
\hline & & $(0.04)$ & $(0.05)$ & $(0.04)$ & $(0.04)$ & $(0.04)$ & $(0.04)$ & $(0.04)$ & $(0.04)$ & $(0.04)$ & $(0.04)$ \\
\hline \multirow[t]{2}{*}{ Hisp Fem, White Collar } & 353 & -.35 & -.03 & -.46 & -.47 & -.45 & -.28 & 0.09 & -.21 & -.08 & -17 \\
\hline & & $(0.03)$ & $(0.03)$ & $(0.02)$ & $(0.02)$ & $(0.02)$ & $(0.02)$ & $(0.04)$ & $(0.03)$ & $(0.03)$ & $(0.03)$ \\
\hline \multirow[t]{2}{*}{ Hisp Fem, Blue Collar } & 185 & -.59 & -.41 & -.66 & -.63 & -.62 & -.54 & -.31 &. .52 &. .47 & -.54 \\
\hline & & $(0.04)$ & $(0.05)$ & $(0.03)$ & $(0.03)$ & $(0.03)$ & $(0.03)$ & $(0.06)$ & $(0.03)$ & $(0.05)$ & (0.04) \\
\hline \multirow[t]{2}{*}{ Difference: } & 538 & 0.25 & 0.38 & 0.19 & 0.16 & 0.17 & 0.26 & 0.40 & 0.31 & 0.40 & 0.37 \\
\hline & & $(0.05)$ & $(0.06)$ & $(0.04)$ & $(0.04)$ & $(0.04)$ & $(0.04)$ & $(0.07)$ & $(0.04)$ & $(0.06)$ & $(0.05)$ \\
\hline \multirow[t]{2}{*}{ Hisp Male, White Collar } & 216 & -.05 & .08 & 0.06 & 0.08 & 0.01 & $0.0 t$ & -.11 & 0.01 & .05 & -.08 \\
\hline & & $(0.04)$ & $(0.04)$ & $(0.04)$ & $(0.04)$ & $(0.04)$ & $(0.04)$ & $(0.05)$ & $(0.04)$ & $(0.04)$ & $(0.04)$ \\
\hline \multirow[t]{2}{*}{ Hisp Male, Blue Collar } & 411 & -.44 & -.48 & -.09 & -.23 & -.30 & -.41 & -.50 & -.43 & -.52 & -.45 \\
\hline & & $(0.03)$ & $(0.03)$ & $(0.03)$ & $(0.03)$ & $(0.03)$ & $(0.02)$ & $(0.03)$ & $(0.02)$ & $(0.03)$ & $(0.03)$ \\
\hline \multirow[t]{2}{*}{ Difference: } & 627 & 0.38 & 0.40 & 0.16 & 0.31 & 0.31 & 0.42 & 0.39 & 0.44 & 0.46 & 0.37 \\
\hline & & $(0.06)$ & $(0.05)$ & $(0.05)$ & $(0.06)$ & $(0.05)$ & $(0.05)$ & $(0.06)$ & $(0.05)$ & $(0.05)$ & $(0.05)$ \\
\hline \multirow[t]{2}{*}{ White Fem, White Collar } & 1349 & 0.13 & 0.34 & -.16 &. .04 & -.02 & 0.18 & 0.44 & 0.21 & 0.28 & 0.24 \\
\hline & & $(0.01)$ & $(0.01)$ & $(0.01)$ & $(0.01)$ & $(0.01)$ & $(0.01)$ & $(0.02)$ & $(0.02)$ & $(0.01)$ & $(0.01)$ \\
\hline \multirow[t]{2}{*}{ White Fem, Blue Collar } & 586 & -.16 & -.07 & -.28 & -.30 & -.20 & -.21 & 0.08 & -.22 & -.01 & -.04 \\
\hline & & $(0.02)$ & $(0.03)$ & $(0.02)$ & $(0.02)$ & $(0.02)$ & $(0.02)$ & $(0.03)$ & $(0.02)$ & $(0.02)$ & $(0.02)$ \\
\hline \multirow[t]{2}{*}{ Difference: } & 1935 & 0.28 & 0.41 & 0.11 & 0.26 & 0.19 & 0.39 & 0.36 & 0.44 & 0.29 & 0.29 \\
\hline & & $(0.02)$ & $(0.03)$ & $(0.02)$ & $(0.02)$ & $(0.02)$ & $(0.03)$ & $(0.03)$ & $(0.03)$ & $(0.02)$ & $(0.02)$ \\
\hline \multirow[t]{2}{*}{ White Male, White Collar } & 889 & 0.48 & 0.30 & 0.51 & 0.55 & 0.52 & 0.46 & 0.22 & 0.46 & 0.27 & 0.32 \\
\hline & & $(0.02)$ & $(0.02)$ & $(0.02)$ & $(0.02)$ & $(0.02)$ & $(0.02)$ & $(0.02)$ & $(0.02)$ & $(0.01)$ & $(0.01)$ \\
\hline \multirow[t]{2}{*}{ White Male, Blue Collar } & 1089 & 0.08 & -.16 & 0.46 & 0.28 & 0.24 & -.00 & -.23 & -.13 & -.11 & -.04 \\
\hline & & $(0.02)$ & $(0.02)$ & $(0.02)$ & $(0.02)$ & $(0.02)$ & $(0.02)$ & $(0.02)$ & $(0.02)$ & $(0.02)$ & $(0.02)$ \\
\hline \multirow[t]{2}{*}{ Difference: } & 1978 & 0.41 & 0.46 & 0.05 & 0.27 & 0.28 & 0.46 & 0.45 & 0.59 & 0.38 & 0.37 \\
\hline & & $(0.02)$ & $(0.03)$ & $(0.02)$ & $(0.03)$ & $(0.02)$ & $(0.02)$ & $(0.03)$ & $(0.03)$ & $(0.02)$ & $(0.02)$ \\
\hline
\end{tabular}

1. Tahle creaced on 08MAR9? 


\begin{tabular}{|c|c|c|c|c|c|c|}
\hline \multicolumn{7}{|c|}{$\begin{array}{l}\text { TABLE 6: LOG WAGE REGRESSION } \\
\text { UNCONDITIONAL ON OCCUPATION } \\
\text { Eicker-White standard errors appear in parentheses }\end{array}$} \\
\hline Yariable & Black Females & Black Males & Hispanic Females & Hispanic Males & White Females & White Males \\
\hline lst Principal Component (g) & $\begin{array}{r}0.1565(0.0151) \\
p=0.0000\end{array}$ & $\begin{array}{cc}0.1191 & (0.0139) \\
p= & 0.0000\end{array}$ & $\begin{array}{cc}0.1124 & (0.0190) \\
p= & 0.0000\end{array}$ & $\begin{array}{c}0.1376 \quad(0.0194) \\
p=0.0000\end{array}$ & $\begin{array}{c}0.1090(0.0103) \\
P=0.0000\end{array}$ & $\begin{array}{cc}0.1027 & (0.0106) \\
p= & 0.0000\end{array}$ \\
\hline 2nd Principal Component & $\begin{array}{rc}-0.0415 & (0.0109) \\
p= & 0.0001\end{array}$ & $\begin{array}{cc}-0.0022 & (0.0109) \\
p= & 0.8406\end{array}$ & $\begin{array}{c}0.0255 \quad(0.0136) \\
p=0.0612\end{array}$ & $\begin{array}{c}0.0308 \quad(0.0133) \\
p=0.0208\end{array}$ & $\begin{array}{r}0.0706 \quad(0.0081) \\
p=0.0000\end{array}$ & $\begin{array}{rr}0.0045 & (0.0080) \\
p= & 0.5743\end{array}$ \\
\hline 3rd Principal Component & $\begin{array}{cc}0.0107 \quad(0.0112) \\
p=0.3395\end{array}$ & $\begin{array}{rc}-0.0024 & (0.0107) \\
p= & 0.8213\end{array}$ & $\begin{array}{cc}0.0336 & (0.0134) \\
p= & 0.0122\end{array}$ & $\begin{array}{cc}0.0718 & (0.0154) \\
p= & 0.0000\end{array}$ & $\begin{array}{cc}-0.0046 & (0.0074) \\
p= & 0.5322\end{array}$ & $\begin{array}{cc}0.0741 & (0.0077) \\
P & =0.0000\end{array}$ \\
\hline 4th Principal Component & $\begin{array}{cc}-0.0072 & (0.0111) \\
p= & 0.5180\end{array}$ & $\begin{array}{cc}0.0320 & (0.0115) \\
p= & 0.0056\end{array}$ & $\begin{array}{rc}0.0035 & (0.0127) \\
p= & 0.7800\end{array}$ & $\begin{array}{cc}0.0338 & (0.0149) \\
p= & 0.0231\end{array}$ & $\begin{array}{c}0.0169(0.0078) \\
p=0.0311\end{array}$ & $\begin{array}{cc}0.0109 & (0.0077) \\
p= & 0.1575\end{array}$ \\
\hline 5th Principal Component & $\begin{array}{rc}-0.0016 & (0.0104) \\
p= & 0.8791\end{array}$ & $\begin{array}{cc}0.0327 & (0.0108) \\
p= & 0.0025\end{array}$ & $\begin{array}{c}-0.0191 \quad(0.0125) \\
\mathrm{p}=0.1275\end{array}$ & $\begin{array}{c}0.0348 \quad(0.0134) \\
p=0.0097\end{array}$ & $\begin{array}{cc}-0.0052 & (0.0074) \\
p= & 0.4803\end{array}$ & $\begin{array}{cc}0.0419 & (0.0074) \\
p= & 0.0000\end{array}$ \\
\hline 6th Principal Component & $\begin{array}{rc}-0.0120 & (0.0112) \\
\mathrm{p} & =0.2857\end{array}$ & $\begin{array}{rc}0.0024 & (0.0108) \\
p= & 0.8209\end{array}$ & $\begin{array}{rc}-0.0137 & (0.0129) \\
p= & 0.2884\end{array}$ & $\begin{array}{cc}0.0041 & (0.0138) \\
p= & 0.7675\end{array}$ & $\begin{array}{cc}-0.0170 & (0.0074) \\
p= & 0.0206\end{array}$ & $\begin{array}{rc}0.0012 & (0.0072) \\
p= & 0.8730\end{array}$ \\
\hline 7th Principal Component & $\begin{aligned}-0.0151 & (0.0104) \\
p= & 0.1465\end{aligned}$ & $\begin{array}{cc}-0.0161 & (0.0099) \\
p= & 0.1050\end{array}$ & $\begin{aligned} 0.0190 & (0.0129) \\
p= & 0.1416\end{aligned}$ & $\begin{array}{rc}0.0194 & (0.0151) \\
p= & 0.1970\end{array}$ & $\begin{array}{rc}0.0119 & (0.0072) \\
p= & 0.0979\end{array}$ & $\begin{array}{cc}0.0043 & (0.0072) \\
p= & 0.5450\end{array}$ \\
\hline 8th Principal Component & $\begin{array}{rc}-0.0072 & (0.0109) \\
\mathbf{p} & =0.5080\end{array}$ & $\begin{array}{rc}0.0173 & (0.0106) \\
p= & 0.1042\end{array}$ & $\begin{array}{rc}-0.0122 & (0.0128) \\
p= & 0.3405\end{array}$ & $\begin{array}{rc}0.0120 & (0.0141) \\
p= & 0.3943\end{array}$ & $\begin{array}{cc}0.0044 & (0.0069) \\
p= & 0.5233\end{array}$ & $\begin{array}{cc}0.0197 & 10.0075) \\
p= & 0.0089\end{array}$ \\
\hline 9th Principal Component & $\begin{array}{r}0.0039(0.0099) \\
p=0.6951\end{array}$ & $\begin{array}{rc}0.0024 & (0.0108) \\
p= & 0.8255\end{array}$ & $\begin{array}{rc}-0.0058 & (0.0122) \\
p= & 0.6331\end{array}$ & $\begin{array}{rc}-0.0096 & (0.0141) \\
p= & 0.4979\end{array}$ & $\begin{array}{rc}-0.0152 & (0.0072) \\
p= & 0.0346\end{array}$ & $\begin{array}{rc}-0.0006 & (0.0071) \\
p= & 0.9344\end{array}$ \\
\hline 10th Principal Component & $\begin{array}{cc}-0.0012 & (0.0110) \\
\mathbf{p}= & 0.9101\end{array}$ & $\begin{array}{rc}0.0091 & (0.0103) \\
p= & 0.3778\end{array}$ & $\begin{array}{rc}-0.0047 & (0.0135) \\
p= & 0.7294\end{array}$ & $\begin{array}{rc}0.0160 & (0.0145) \\
p= & 0.2720\end{array}$ & $\begin{array}{rc}-0.0027 & (0.0072) \\
p= & 0.7104\end{array}$ & $\begin{array}{cc}0.0048 & (0.0074) \\
p= & 0.5167\end{array}$ \\
\hline Grades Completed & $\begin{array}{rc}0.0822 & (0.0058) \\
p= & 0.0000\end{array}$ & $\begin{array}{rc}0.0776 & (0.0054) \\
p= & 0.0000\end{array}$ & $\begin{array}{rc}0.0691 & (0.0065) \\
p= & 0.0000\end{array}$ & $\begin{array}{rc}0.0597 & (0.0063) \\
p= & 0.0000\end{array}$ & $\begin{array}{rc}0.0848 & (0.0035) \\
p= & 0.0000\end{array}$ & $\begin{array}{cc}0.0722 & (0.0034) \\
p= & 0.0000\end{array}$ \\
\hline Potential Experience & $\begin{array}{cc}0.0265 & (0.0020) \\
p= & 0.0000\end{array}$ & $\begin{array}{rc}0.0284 & (0.0019) \\
p= & 0.0000\end{array}$ & $\begin{array}{cc}0.0247 & (0.0024) \\
p= & 0.0000\end{array}$ & $\begin{array}{rc}0.0436 & (0.0023) \\
p= & 0.0000\end{array}$ & $\begin{array}{c}0.0232 \quad(0.0013) \\
p=0.0000\end{array}$ & $\begin{array}{c}0.0381 \quad(0.0013) \\
p=0.0000\end{array}$ \\
\hline Region of Residence: North Central & $\begin{array}{rc}-0.1634 & (0.0291) \\
p= & 0.0000\end{array}$ & $\begin{array}{rc}-0.1327 & (0.0293) \\
p= & 0.0000\end{array}$ & $\begin{array}{rc}-0.1936 & (0.0521) \\
p= & 0.0002\end{array}$ & $\begin{array}{rc}-0.1164 & (0.0471) \\
p= & 0.0135\end{array}$ & $\begin{array}{rc}-0.1346 & (0.0162) \\
p= & 0.0000\end{array}$ & $\begin{array}{rc}-0.1064 & (0.0156) \\
p= & 0.0000\end{array}$ \\
\hline Region of Residence: South & $\begin{array}{rc}-0.1721 & (0.0215) \\
p= & 0.0000\end{array}$ & $\begin{array}{rc}-0.1402 & (0.0238) \\
p= & 0.0000\end{array}$ & $\begin{array}{rc}-0.1673 & (0.0277) \\
p= & 0.0000\end{array}$ & $\begin{array}{rc}-0.1716 & (0.0295) \\
p= & 0.0000\end{array}$ & $\begin{array}{c}-0.1254 \quad(0.0151) \\
p=0.0000\end{array}$ & $\begin{array}{rr}-0.0739 & (0.0147) \\
p= & 0.0000\end{array}$ \\
\hline Region of Residence: West & $\begin{array}{cc}-0.0496 & (0.0338) \\
p= & 0.1421\end{array}$ & $\begin{array}{cc}0.0441 & (0.0372) \\
p & =0.2356\end{array}$ & $\begin{array}{cc}-0.0928 & (0.0274) \\
p= & 0.0007\end{array}$ & $\begin{array}{cc}-0.0355 & (0.0274) \\
p= & 0.1951\end{array}$ & $\begin{array}{cc}-0.0225 & (0.0184) \\
P & =0.2234\end{array}$ & $\begin{array}{cc}-0.0115 & (0.0182) \\
p= & 0.5258\end{array}$ \\
\hline Local Unemployment Rate: $6-9 \%$ & $\begin{array}{rc}-0.0544 & (0.0131) \\
p= & 0.0000\end{array}$ & $\begin{array}{rc}-0.0685 & (0.0116) \\
p= & 0.0000\end{array}$ & $\begin{array}{rc}-0.0486 & (0.0175) \\
p= & 0.0056\end{array}$ & $\begin{array}{cc}-0.0872 & (0.0154) \\
p= & 0.0000\end{array}$ & $\begin{array}{cc}-0.0815 & (0.0090) \\
p= & 0.0000\end{array}$ & $\begin{array}{rr}-0.0560 & (0.0088) \\
p= & 0.00000\end{array}$ \\
\hline Local Unemployment Rate: Over $9 \%$ & $\begin{array}{rc}-0.0906 & (0.0198) \\
p & =0.0000\end{array}$ & $\begin{array}{rc}-0.0949 & (0.0187) \\
p & =0.0000\end{array}$ & $\begin{array}{r}-0.1396 \quad(0.0215) \\
p=0.0000\end{array}$ & $\begin{array}{rc}-0.2103 & (0.0207) \\
p= & 0.0000\end{array}$ & $\begin{array}{rc}-0.1266 & (0.0126) \\
P & =0.0000\end{array}$ & $\begin{array}{rr}-0.1185 & (0.0133) \\
p= & 0.0000\end{array}$ \\
\hline National Unemployment Rate: $6-9 \%$ & $\begin{array}{rc}-0.0163 & (0.0102) \\
p= & 0.1083\end{array}$ & $\begin{array}{rc}-0.0208 & (0.0102) \\
p= & 0.0420\end{array}$ & $\begin{array}{rc}-0.0314 & (0.0133) \\
p= & 0.0187\end{array}$ & $\begin{array}{rc}-0.0002 & (0.0115) \\
p & =0.9871\end{array}$ & $\begin{array}{cc}-0.0081 & (0.0074) \\
p= & 0.2704\end{array}$ & $\begin{array}{rc}-0.0324 & (0.0069) \\
p= & 0.0000\end{array}$ \\
\hline National Unemployment Rate: Over $9 \%$ & $\begin{array}{rc}-0.0189 & (0.0189) \\
p= & 0.3154\end{array}$ & $\begin{array}{rc}-0.0688 & (0.0183) \\
p= & 0.0002\end{array}$ & $\begin{array}{rc}-0.0327 & (0.0213) \\
p= & 0.1257\end{array}$ & $\begin{array}{rc}0.0199 & (0.0200) \\
p= & 0.3205\end{array}$ & $\begin{array}{rc}-0.0009 & (0.0119) \\
p= & 0.9420\end{array}$ & $\begin{array}{rr}-0.0365 & (0.0120) \\
\mathbf{p}= & 0.0023\end{array}$ \\
\hline Year & $\begin{array}{rc}-0.0032 & (0.0010) \\
p= & 0.0010\end{array}$ & $\begin{array}{rc}-0.0083 & (0.0009) \\
p= & 0.0000\end{array}$ & $\begin{aligned} 0.0036 & (0.0011) \\
p= & 0.0011\end{aligned}$ & $\begin{array}{rc}-0.0061 & (0.0010) \\
p= & 0.0000\end{array}$ & $\begin{array}{rc}0.0087 & (0.0006) \\
p= & 0.0000\end{array}$ & $\begin{array}{cc}0.0036 & (0.0006) \\
p= & 0.0000\end{array}$ \\
\hline R-squared & $R^{2}=0.2219$ & $R^{2}=0.1888$ & $R^{2}=0.2036$ & $R^{2}=0.2156$ & $R^{2}=0.2433$ & $R^{2}=0.2483$ \\
\hline Number of Observations & 12391 & 13674 & 8001 & 9200 & 31084 & 32493 \\
\hline
\end{tabular}




\begin{tabular}{|c|c|c|c|c|c|}
\hline \multicolumn{6}{|c|}{$\begin{array}{c}\text { Table } 7 \\
\text { Contribution of Ability to Wage Determination } \\
\text { Modelled With and Without Human Capital } \\
\text { Unconditional on Occupation } \\
\text { All Ability Measures Standardized by Age Cohort }\end{array}$} \\
\hline & \multicolumn{2}{|c|}{ Modelled With Background Variables Only } & \multicolumn{2}{|c|}{ Modelled With Human Capital } & \multirow[b]{2}{*}{ Obs. } \\
\hline Group & AFQT & $\mathbf{g}$ & AFQT & $g$ & \\
\hline Black Females & $\begin{array}{c}0.208 \\
(-0.163) \\
p=-0.162\end{array}$ & $\begin{array}{c}0.244 \\
(-0.166) \\
p=-0.166\end{array}$ & $\begin{array}{c}0.126 \\
(-0.160) \\
p=-0.171\end{array}$ & $\begin{array}{c}0.149 \\
(-0.162) \\
p=-0.173\end{array}$ & 12391 \\
\hline Change in $R^{2}=$ & 0.172 & 0.174 & 0.026 & 0.027 & \\
\hline Black Males & $\begin{array}{c}0.157 \\
(-0.117) \\
p=-0.119\end{array}$ & $\begin{array}{c}0.209 \\
(-0.121) \\
p=-0.117\end{array}$ & $\begin{array}{c}0.086 \\
(-0.124) \\
p=-0.132\end{array}$ & $\begin{array}{c}0.123 \\
(-0.126) \\
p=-0.130\end{array}$ & 13674 \\
\hline Change in $R^{2}=$ & 0.140 & 0.148 & 0.013 & 0.017 & \\
\hline Hispanic Females & $\begin{array}{c}0.166 \\
(-0.227) \\
p=-0.179\end{array}$ & $\begin{array}{c}0.206 \\
(-0.246) \\
p=-0.197\end{array}$ & $\begin{array}{c}0.086 \\
(-0.186) \\
p=-0.167\end{array}$ & $\begin{array}{c}0.107 \\
(-0.197) \\
p=-0.176\end{array}$ & 8001 \\
\hline Change in $R^{2}=$ & 0.162 & 0.165 & 0.013 & 0.013 & \\
\hline Hispanic Males & $\begin{array}{c}0.104 \\
(-0.071) \\
p=-0.144\end{array}$ & $\begin{array}{c}0.189 \\
(-0.081) \\
p=-0.160\end{array}$ & $\begin{array}{c}0.063 \\
(-0.081) \\
p=-0.137\end{array}$ & $\begin{array}{c}0.131 \\
(-0.090) \\
p=-0.150\end{array}$ & 9200 \\
\hline Change in $R^{2}=$ & 0.147 & 0.160 & 0.008 & 0.014 & \\
\hline White Females & $\begin{array}{c}0.185 \\
(-0.156) \\
p=-0.137\end{array}$ & $\begin{array}{c}0.238 \\
(-0.163) \\
p=-0.147\end{array}$ & $p=\begin{array}{c}0.082 \\
(-0.132) \\
-0.131\end{array}$ & $\begin{array}{c}0.105 \\
(-0.135) \\
p=-0.135\end{array}$ & 31084 \\
\hline Change in $R^{2}=$ & 0.188 & 0.189 & 0.009 & 0.010 & \\
\hline White Males & $\begin{array}{c}0.132 \\
(-0.079) \\
p=-0.061\end{array}$ & $\begin{array}{c}0.208 \\
(-0.092) \\
p=-0.065\end{array}$ & $\begin{array}{c}0.061 \\
(-0.079) \\
p=-0.069\end{array}$ & $\begin{array}{c}0.112 \\
(-0.086) \\
p=-0.070\end{array}$ & 32493 \\
\hline Change in $R^{2}=$ & 0.186 & 0.199 & 0.007 & 0.011 & \\
\hline
\end{tabular}




\begin{tabular}{|c|c|c|c|c|c|c|}
\hline \multicolumn{7}{|c|}{$\begin{array}{l}\text { TABLE 8: LOG WAGE REGRESSION } \\
\text { CONDITIONAL ON BLUE COLLAR OCCUPATION } \\
\text { Eicker-White standard errors are listed in parentheses }\end{array}$} \\
\hline Variable & Black Females & Black Males & Hispanic Females & Hispanic Males & White Females & White Males \\
\hline Ist Principal Component (g) & $\begin{array}{rc}0.1138 & (0.0229) \\
p= & 0.0000\end{array}$ & $\begin{array}{rc}0.0993 & (0.0158) \\
p= & 0.0000\end{array}$ & $\begin{array}{rc}0.0561 & (0.0302) \\
p= & 0.0631\end{array}$ & $\begin{array}{rc}0.1322 & (0.0215) \\
p= & 0.0000\end{array}$ & $\begin{array}{cc}0.0641 & (0.0159) \\
p= & 0.0001\end{array}$ & $\begin{array}{rr}0.0926 & (0.0120) \\
p= & 0.0000\end{array}$ \\
\hline 2nd Principal Component & $\begin{array}{rc}-0.0165 & (0.0160) \\
p= & 0.3006\end{array}$ & $\begin{array}{cc}-0.0062 & (0.0126) \\
p= & 0.6233\end{array}$ & $\begin{array}{rc}-0.0014 & (0.0255) \\
p= & 0.9549\end{array}$ & $\begin{array}{cc}0.0195 & (0.0152) \\
p= & 0.1988\end{array}$ & $\begin{array}{rc}0.0586 & (0.0128) \\
p= & 0.0000\end{array}$ & $\begin{array}{rc}-0.0139 & (0.0094) \\
p & =0.1382\end{array}$ \\
\hline 3rd Principal Component & $\begin{array}{rc}-0.0054 & (0.0162) \\
p= & 0.7407\end{array}$ & $\begin{array}{rc}0.0137 & (0.0124) \\
p= & 0.2698\end{array}$ & $\begin{array}{rc}0.0051 & (0.0246) \\
p= & 0.8345\end{array}$ & $\begin{array}{cc}0.0954 & (0.0171) \\
p= & 0.0000\end{array}$ & $\begin{array}{cc}0.0334 & (0.0127) \\
p= & 0.0086\end{array}$ & $\begin{array}{cc}0.0864 & (0.0091) \\
p= & 0.0000\end{array}$ \\
\hline 4th Principal Component & $\begin{array}{rc}0.0233 & (0.0168) \\
p= & 0.1664\end{array}$ & $\begin{array}{rc}0.0294 & (0.0131) \\
p= & 0.0252\end{array}$ & $\begin{array}{rc}-0.0022 & (0.0235) \\
p= & 0.9241\end{array}$ & $\begin{array}{cc}0.0410 & (0.0179) \\
p= & 0.0218\end{array}$ & $\begin{array}{cc}0.0465 & (0.0127) \\
p= & 0.0002\end{array}$ & $\begin{array}{rc}-0.0061 & (0.0089) \\
p= & 0.4882\end{array}$ \\
\hline 5th Principal Component & $\begin{array}{rc}-0.0144 & (0.0155) \\
p= & 0.3499\end{array}$ & $\begin{array}{rc}0.0368 & (0.0121) \\
p= & 0.0023\end{array}$ & $\begin{array}{rc}-0.0427 & (0.0243) \\
\mathrm{p}= & 0.0781\end{array}$ & $\begin{array}{cc}0.0481 & (0.0152) \\
p= & 0.0016\end{array}$ & $\begin{array}{rc}-0.0207 & (0.0119) \\
\mathrm{p}= & 0.0820\end{array}$ & $\begin{array}{rr}0.0520 & (0.0086) \\
p= & 0.0000\end{array}$ \\
\hline 6th Principal Component & $\begin{array}{rc}-0.0093 & (0.0148) \\
p= & 0.5322\end{array}$ & $\begin{array}{rc}-0.0034 & (0.0123) \\
p= & 0.7812\end{array}$ & $\begin{array}{rc}-0.0190 & (0.0219) \\
p= & 0.3869\end{array}$ & $\begin{array}{cc}0.0005 & (0.0147) \\
p= & 0.9752\end{array}$ & $\begin{array}{rc}-0.0257 & (0.0115) \\
p= & 0.0253\end{array}$ & $\begin{array}{cc}0.0105 & (0.0082) \\
p= & 0.2011\end{array}$ \\
\hline 7th Principal Component & $\begin{aligned}-0.0230 & (0.0161) \\
p & =0.1532\end{aligned}$ & $\begin{array}{rc}-0.0162 & (0.0111) \\
p= & 0.1455\end{array}$ & $\begin{array}{rc}0.0106 & (0.0202) \\
p= & 0.5992\end{array}$ & $\begin{array}{rc}0.0441 & (0.0158) \\
p= & 0.0051\end{array}$ & $\begin{array}{cc}0.0222 & (0.0109) \\
p= & 0.0412\end{array}$ & $\begin{array}{rc}-0.0013 & (0.0082) \\
p= & 0.8759\end{array}$ \\
\hline 8th Principal Component & $\begin{array}{rc}-0.0187 & (0.0147) \\
p= & 0.2048\end{array}$ & $\begin{array}{cc}0.0221 & (0.0121) \\
p & =0.0678\end{array}$ & $\begin{array}{rc}-0.0454 & (0.0229) \\
p= & 0.0472\end{array}$ & $\begin{array}{cc}0.0073 & (0.0153) \\
p= & 0.6354\end{array}$ & $\begin{array}{rc}-0.0037 & (0.0111) \\
p= & 0.7412\end{array}$ & $\begin{array}{cc}0.0144 & (0.0085) \\
p= & 0.0900\end{array}$ \\
\hline 9th Principal Component & $\begin{array}{rc}-0.0174 & (0.0137) \\
p= & 0.2014\end{array}$ & $\begin{array}{rc}-0.0081 & (0.0119) \\
p= & 0.4947\end{array}$ & $\begin{array}{cc}0.0073 & (0.0227) \\
p= & 0.7474\end{array}$ & $\begin{array}{rc}-0.0209 & (0.0161) \\
p= & 0.1943\end{array}$ & $\begin{array}{rc}-0.0110 & (0.0107) \\
p= & 0.3060\end{array}$ & $\begin{array}{rc}-0.0092 & (0.0084) \\
p= & 0.2686\end{array}$ \\
\hline 10th Principal Component & $\begin{array}{cc}0.0062 & (0.0140) \\
p= & 0.6580\end{array}$ & $\begin{array}{cc}0.0042 & (0.0112) \\
p & =0.7077\end{array}$ & $\begin{array}{rc}-0.0153 & (0.0215) \\
p= & 0.4747\end{array}$ & $\begin{array}{cc}0.0204 & (0.0148) \\
p= & 0.1686\end{array}$ & $\begin{array}{rc}-0.0010 & (0.0108) \\
p= & 0.9291\end{array}$ & $\begin{array}{rc}0.0009 & (0.0082) \\
p= & 0.9143\end{array}$ \\
\hline Grades Completed & $\begin{array}{rc}0.0579 & (0.0098) \\
p= & 0.0000\end{array}$ & $\begin{array}{cc}0.0610 & (0.0062) \\
p= & 0.0000\end{array}$ & $\begin{aligned} 0.0497 & (0.0103) \\
p & =0.0000\end{aligned}$ & $\begin{array}{cc}0.0491 & (0.0069) \\
P= & 0.0000\end{array}$ & $\begin{array}{cc}0.0690 & (0.0057) \\
p= & 0.0000\end{array}$ & $\begin{array}{cc}0.0521 & (0.0046) \\
p= & 0.0000\end{array}$ \\
\hline Potential Experience & $\begin{array}{cc}0.0159 & (0.0030) \\
p & =0.0000\end{array}$ & $\begin{array}{rc}0.0265 & (0.0021) \\
p= & 0.0000\end{array}$ & $\begin{array}{rc}0.0246 & (0.0040) \\
p= & 0.0000\end{array}$ & $\begin{array}{cc}0.0405 & (0.0025) \\
p= & 0.0000\end{array}$ & $\begin{array}{rc}0.0254 & (0.0021) \\
p= & 0.0000\end{array}$ & $\begin{array}{cc}0.0372 & (0.0015) \\
p= & 0.0000\end{array}$ \\
\hline Region of Residence: North Central & $\begin{array}{cc}-0.1039 & (0.0465) \\
p= & 0.0255\end{array}$ & $\begin{array}{cc}-0.1013 & (0.0346) \\
p= & 0.0034\end{array}$ & $\begin{array}{rc}-0.2237 & (0.0964) \\
p= & 0.0203\end{array}$ & $\begin{array}{rc}-0.1740 & (0.0523) \\
p= & 0.0009\end{array}$ & $\begin{array}{rc}-0.1496 & (0.0256) \\
p= & 0.0000\end{array}$ & $\begin{array}{rc}-0.1064 & (0.0182) \\
p & =0.0000\end{array}$ \\
\hline Region of Residence: South & $\begin{array}{rc}-0.1271 & (0.0364) \\
p= & 0.0005\end{array}$ & $\begin{array}{rc}-0.1204 & (0.0279) \\
p= & 0.0000\end{array}$ & $\begin{array}{cc}-0.1594 & (0.0556) \\
p= & 0.0042\end{array}$ & $\begin{array}{rc}-0.1992 & (0.0321) \\
p= & 0.0000\end{array}$ & $\begin{array}{rc}-0.1003 & (0.0244) \\
p= & 0.0000\end{array}$ & $\begin{array}{rr}-0.0704 & (0.0172) \\
p= & 0.0000\end{array}$ \\
\hline Region of Residence: West & $\begin{array}{rc}-0.0642 & (0.0582) \\
p= & 0.2693\end{array}$ & $\begin{array}{cc}0.0757 & (0.0457) \\
p= & 0.0972\end{array}$ & $\begin{array}{rc}-0.0139 & (0.0535) \\
p= & 0.7949\end{array}$ & $\begin{array}{rc}-0.0529 & (0.0310) \\
p= & 0.0873\end{array}$ & $\begin{array}{rc}-0.0547 & (0.0288) \\
p= & 0.0577\end{array}$ & $\begin{array}{cc}0.0054 & (0.0218) \\
p= & 0.8057\end{array}$ \\
\hline Local Unemployment Rate: $6-9 \%$ & $\begin{array}{rc}-0.0202 & (0.0194) \\
p= & 0.2983\end{array}$ & $\begin{array}{rc}-0.0645 & (0.0128) \\
p= & 0.0000\end{array}$ & $\begin{array}{rc}-0.0141 & (0.0327) \\
p= & 0.6670\end{array}$ & $\begin{array}{rc}-0.0933 & (0.0182) \\
p= & 0.0000\end{array}$ & $\begin{array}{rc}-0.0518 & (0.0166) \\
p= & 0.0018\end{array}$ & $\begin{array}{cc}-0.0612 & (0.0105) \\
p= & 0.0000\end{array}$ \\
\hline Local Unemployment Rate: Over $9 \%$ & $\begin{array}{rc}-0.0624 & (0.0307) \\
p= & 0.0419\end{array}$ & $\begin{array}{rc}-0.0895 & (0.0202) \\
p= & 0.0000\end{array}$ & $\begin{array}{rc}-0.0865 & (0.0379) \\
p= & 0.0225\end{array}$ & $\begin{array}{rc}-0.2081 & (0.0237) \\
p= & 0.0000\end{array}$ & $\begin{array}{cc}-0.0867 & (0.0220) \\
p= & 0.0001\end{array}$ & $\begin{array}{rc}.0 .1196 & (0.0154) \\
p= & 0.0000\end{array}$ \\
\hline National Unemployment Rate: 6-9\% & $\begin{array}{rc}-0.0283 & (0.0166) \\
p= & 0.0883\end{array}$ & $\begin{array}{rc}-0.0141 & (0.0113) \\
p= & 0.2110\end{array}$ & $\begin{array}{rc}-0.0319 & (0.0266) \\
p= & 0.2304\end{array}$ & $\begin{array}{cc}0.0101 & (0.0137) \\
p= & 0.4624\end{array}$ & $\begin{array}{rc}0.0073 & (0.0141) \\
p= & 0.6054\end{array}$ & $\begin{array}{cc}.0 .0124 & (0.0087) \\
p= & 0.1506\end{array}$ \\
\hline National Unemployment Rate: Over $9 \%$ & $\begin{array}{rc}-0.0297 & (0.0299) \\
p= & 0.3194\end{array}$ & $\begin{array}{cc}-0.0575 & (0.0202) \\
\mathrm{p}= & 0.0045\end{array}$ & $\begin{array}{rc}-0.0402 & (0.0397) \\
p= & 0.3117\end{array}$ & $\begin{array}{cc}0.0198 & (0.0223) \\
p= & 0.3752\end{array}$ & $\begin{array}{cc}0.0095 & (0.0212) \\
p= & 0.6534\end{array}$ & $\begin{array}{cc}-0.0193 & (0.0139) \\
p= & 0.1635\end{array}$ \\
\hline Year & $\begin{array}{rc}-0.0032 & (0.0016) \\
p= & 0.0403\end{array}$ & $\begin{array}{cc}-0.0102 & (0.0010) \\
p= & 0.0000\end{array}$ & $\begin{array}{cc}-0.0095 & (0.0018) \\
p= & 0.0000\end{array}$ & $\begin{array}{rc}-0.0054 & (0.0011) \\
p= & 0.0000\end{array}$ & $\begin{array}{rc}-0.0065 & (0.0009) \\
p= & 0.0000\end{array}$ & $\begin{array}{cc}-0.0026 & (0.0008\} \\
p= & 0.0005\end{array}$ \\
\hline $\begin{array}{l}\text { R-squared } \\
\text { Number of Observations }\end{array}$ & $\begin{array}{l}R^{2}=0.0894 \\
5435\end{array}$ & $\begin{array}{l}R^{2}=0.1218 \\
10257\end{array}$ & $\begin{array}{l}R^{2}=0.0817 \\
2765\end{array}$ & $\begin{array}{l}R^{2}=0.2144 \\
6473\end{array}$ & $\begin{array}{l}R^{2}=0.0994 \\
11585\end{array}$ & $\begin{array}{l}R^{2}=0.1845 \\
21049\end{array}$ \\
\hline
\end{tabular}

Sample includes all valid employed oul-or school person-year observauions.

OLS regression used with stacked person-year observations.

Dependens variable is the log of the hourly wage reported for each year in 1540 do llars.

Regressions run separately for race-sex groups based on rejection of the hypothesis that coefficients are equal across groups.

Reported scandard errors are Eicker-White mbust standard errors generalized for panel data. 


\begin{tabular}{|c|c|c|c|c|c|}
\hline \multicolumn{6}{|c|}{$\begin{array}{c}\text { Table 9 } \\
\text { Contribution of Ability to Blue Collar Wage Determination } \\
\text { Modelled With and Without Human Capital } \\
\text { All Ability Measures Standardized by Age Cohort }\end{array}$} \\
\hline & \multicolumn{2}{|c|}{ Modelled With Background Variables Only } & \multicolumn{2}{|c|}{ Modelled With Human Capital } & \multirow[b]{2}{*}{ Obs. } \\
\hline Group & AFQT & $\mathrm{g}$ & AFQT & $\mathrm{g}$ & \\
\hline Black Females & $p=\begin{array}{c}0.141 \\
(-0.090) \\
p=-0.122\end{array}$ & $\begin{array}{r}0.172 \\
(-0.091) \\
p=-0.124\end{array}$ & $\begin{array}{r}0.094 \\
(-0.096) \\
p=-0.124\end{array}$ & $\begin{array}{r}0.120 \\
(-0.096) \\
p=-0.124\end{array}$ & 5435 \\
\hline Change in $R^{2}=$ & 0.060 & 0.067 & 0.013 & 0.016 & \\
\hline Black Males & $\begin{array}{c}0.111 \\
(-0.091) \\
p=-0.111\end{array}$ & $\begin{array}{c}0.156 \\
(-0.093) \\
p=-0.107\end{array}$ & $\begin{array}{r}0.071 \\
(-0.094) \\
p=-0.118\end{array}$ & $\begin{aligned} & 0.107 \\
&(-0.096) \\
& p=-0.115\end{aligned}$ & 10257 \\
\hline Change in $R^{2}=$ & 0.081 & 0.090 & 0.009 & 0.014 & \\
\hline Hispanic Females & $\begin{array}{c}0.100 \\
(-0.248) \\
p=-0.165\end{array}$ & $\begin{aligned} & 0.115 \\
&(-0.255) \\
& p=-0.172\end{aligned}$ & $\begin{array}{c}0.055 \\
(-0.214) \\
p=-0.155\end{array}$ & $\begin{array}{c}0.058 \\
(-0.216) \\
p=-0.158\end{array}$ & 2765 \\
\hline Change in $R^{2}=$ & 0.057 & 0.057 & 0.004 & 0.003 & \\
\hline Hispanic Males & $\begin{array}{c}0.096 \\
(-0.096) \\
p=-0.153\end{array}$ & $\begin{array}{c}0.177 \\
(-0.107) \\
p=-0.169\end{array}$ & $\begin{array}{c}0.069 \\
(-0.119) \\
p=-0.152\end{array}$ & $\begin{array}{c}0.143 \\
(-0.129) \\
p=-0.166\end{array}$ & 6473 \\
\hline Change in $R^{2}=$ & 0.133 & 0.147 & 0.010 & 0.018 & \\
\hline White Females & $\begin{array}{c}0.099 \\
(-0.157) \\
p=-0.112\end{array}$ & $\begin{array}{c}0.139 \\
(-0.158) \\
p=-0.114\end{array}$ & $\begin{array}{c}0.042 \\
(-0.143) \\
p=-0.100\end{array}$ & $\begin{array}{c}0.067 \\
(-0.144) \\
p=-0.101\end{array}$ & 11585 \\
\hline Change in $R^{2}=$ & 0.059 & 0.064 & 0.003 & 0.004 & \\
\hline White Males & $\begin{array}{c}0.097 \\
(-0.073) \\
p=-0.058\end{array}$ & $\begin{array}{c}0.161 \\
(-0.083) \\
p=-0.059\end{array}$ & $\begin{array}{c}0.060 \\
(-0.077) \\
p=-0.064\end{array}$ & $\begin{array}{c}0.113 \\
(-0.084) \\
p=-0.065\end{array}$ & 21049 \\
\hline Change in $R^{2}=$ & 0.118 & 0.133 & 0.008 & 0.015 & \\
\hline
\end{tabular}




\begin{tabular}{|c|c|c|c|c|c|c|}
\hline \multicolumn{7}{|c|}{$\begin{array}{l}\text { TABLE 10: LOG WAGE REGRESSION } \\
\text { CONDITIONAL ON WHITE COLLAR OCCUPATION } \\
\text { Eicker-White standard errors are listed in parentheses }\end{array}$} \\
\hline Variable & Black Females & Black Males & Hispanic Females & Hispanic Males & White Females & White Males \\
\hline ist Principal Component (g) & $\begin{array}{rc}0.1478 & (0.0182) \\
p= & 0.0000\end{array}$ & $\begin{array}{c}0.1243 \quad(0.0251) \\
p=0.0000\end{array}$ & $\begin{array}{c}0.1212(0.0212) \\
p=0.0000\end{array}$ & $\begin{array}{c}0.1400(0.0358) \\
p=0.0001\end{array}$ & $\begin{array}{rc}0.1083 & (0.0113) \\
p= & 0.0000\end{array}$ & $\begin{array}{rc}0.1089 & (0.0180) \\
p= & 0.0000\end{array}$ \\
\hline 2nd Principal Component & $\begin{array}{cc}-0.0481 & (0.0136) \\
p= & 0.0004\end{array}$ & $\begin{array}{c}0.0126 \quad(0.0169) \\
p=0.4545\end{array}$ & $\begin{array}{c}0.0424 \quad(0.0140) \\
p=0.0024\end{array}$ & $\begin{array}{cc}0.0507 & (0.0208) \\
p= & 0.0149\end{array}$ & $\begin{array}{rc}0.0597 & (0.0086) \\
p= & 0.0000\end{array}$ & $\begin{array}{rc}0.0230 & (0.0124) \\
p= & 0.0643\end{array}$ \\
\hline 3rd Principal Component & $\begin{aligned} 0.0201 & (0.0135) \\
p= & 0.1356\end{aligned}$ & $\begin{array}{rc}-0.0013 & (0.0186) \\
p= & 0.9433\end{array}$ & $\begin{array}{rc}0.0296 & (0.0133) \\
p= & 0.0253\end{array}$ & $\begin{array}{cc}0.0434 & (0.0243) \\
p= & 0.0737\end{array}$ & $\begin{array}{rc}-0.0151 & (0.0076) \\
p= & 0.0477\end{array}$ & $\begin{array}{rr}0.0636 & (0.0112) \\
p= & 0.0000\end{array}$ \\
\hline 4th Principal Component & $\begin{array}{rc}-0.0181 & (0.0130) \\
p= & 0.1646\end{array}$ & $\begin{array}{cc}0.0317 & (0.0194) \\
p= & 0.1013\end{array}$ & $\begin{array}{cc}0.0142 & (0.0133) \\
p= & 0.2856\end{array}$ & $\begin{array}{c}0.0209 \quad(0.0207) \\
p=0.3126\end{array}$ & $\begin{array}{rc}0.0019 & (0.0083) \\
p= & 0.8166\end{array}$ & $\begin{array}{cc}0.0332 & (0.0122) \\
p= & 0.0066\end{array}$ \\
\hline Sth Principal Component & $\begin{array}{rc}0.0065 & (0.0123) \\
p= & 0.5981\end{array}$ & $\begin{array}{rc}0.0217 & (0.0188) \\
p= & 0.2484\end{array}$ & $\begin{array}{rc}-0.0150 & (0.0125) \\
p= & 0.2274\end{array}$ & $\begin{array}{cc}0.0146 & (0.0193) \\
p= & 0.4500\end{array}$ & $\begin{array}{rc}0.0045 & (0.0077) \\
p= & 0.5559\end{array}$ & $\begin{array}{cc}0.0320 & (0.0110) \\
p= & 0.0037\end{array}$ \\
\hline 6th Principal Component & $\begin{array}{rc}-0.0110 & (0.0146) \\
p= & 0.4543\end{array}$ & $\begin{array}{cc}0.0085 & (0.0185) \\
p= & 0.6474\end{array}$ & $\begin{array}{rc}-0.0100 & (0.0131) \\
p= & 0.4452\end{array}$ & $\begin{array}{rc}-0.0019 & (0.0236) \\
p= & 0.9368\end{array}$ & $\begin{array}{cc}-0.0110 & (0.0079) \\
p= & 0.1662\end{array}$ & $\begin{array}{rc}-0.0061 & (0.0112) \\
p= & 0.5852\end{array}$ \\
\hline 7th Principal Component & $\begin{array}{rc}-0.0078 & (0.0117) \\
p= & 0.5033\end{array}$ & $\begin{array}{rc}-0.0309 & (0.0160) \\
p= & 0.0542\end{array}$ & $\begin{array}{rc}0.0322 & (0.0142) \\
p= & 0.0239\end{array}$ & $\begin{array}{rc}-0.0296 & (0.0240) \\
p= & 0.2170\end{array}$ & $\begin{array}{rc}0.0082 & (0.0077) \\
p= & 0.2855\end{array}$ & $\begin{array}{cc}0.0149 & (0.0113) \\
p= & 0.1872\end{array}$ \\
\hline 8th Principal Component & $\begin{array}{rc}0.0047 & (0.0135) \\
p= & 0.7285\end{array}$ & $\begin{array}{c}0.0153(0.0183) \\
p=0.4008\end{array}$ & $\begin{array}{cc}0.0107 & (0.0132) \\
p= & 0.4205\end{array}$ & $\begin{array}{cc}0.0212 & (0.0236) \\
p= & 0.3677\end{array}$ & $\begin{array}{r}0.0035 \quad(0.0076) \\
p=0.6483\end{array}$ & $\begin{array}{rr}0.0235 & (0.0121) \\
p= & 0.0522\end{array}$ \\
\hline 9th Principal Component & $\begin{array}{c}0.0137 \quad(0.0123) \\
p=0.2661\end{array}$ & $\begin{array}{cc}0.0159 & (0.0186) \\
\mathbf{p}= & 0.3913\end{array}$ & $\begin{array}{rc}-0.0159 & (0.0127) \\
p= & 0.2116\end{array}$ & $\begin{array}{cc}0.0142 & (0.0214) \\
p= & 0.5091\end{array}$ & $\begin{array}{rc}-0.0156 & (0.0078) \\
p= & 0.0449\end{array}$ & $\begin{array}{rc}0.0200 & (0.0112) \\
p= & 0.0746\end{array}$ \\
\hline 10th Principal Component & $\begin{array}{rc}-0.0107 & (0.0146) \\
p= & 0.4642\end{array}$ & $\begin{aligned} 0.0198 & (0.0193) \\
p= & 0.3043\end{aligned}$ & $\begin{array}{cc}0.0076 & (0.0151) \\
p= & 0.6155\end{array}$ & $\begin{array}{rc}0.0178 & (0.0282) \\
p= & 0.5270\end{array}$ & $\begin{array}{rc}-0.0058 & (0.0080) \\
p= & 0.4659\end{array}$ & $\begin{array}{rr}0.0052 & (0.0124) \\
p= & 0.6759\end{array}$ \\
\hline Grades Completed & $\begin{array}{cc}0.0836 & (0.0066) \\
p= & 0.0000\end{array}$ & $\begin{array}{cc}0.0940 & (0.0092) \\
p= & 0.0000\end{array}$ & $\begin{array}{cc}0.0743 & (0.0073) \\
p= & 0.0000\end{array}$ & $\begin{array}{cc}0.0704 & (0.0105) \\
p= & 0.0000\end{array}$ & $\begin{array}{rc}0.0753 & (0.0039) \\
p= & 0.0000\end{array}$ & $\begin{array}{rc}0.0786 & (0.0047) \\
p= & 0.0000\end{array}$ \\
\hline Potential Experience & $\begin{array}{rc}0.0366 & (0.0024) \\
p= & 0.0000\end{array}$ & $\begin{array}{rc}0.0343 & (0.0039) \\
p= & 0.0000\end{array}$ & $\begin{array}{rc}0.0224 & (0.0026) \\
p= & 0.0000\end{array}$ & $\begin{aligned} 0.0472 & (0.0041) \\
p= & 0.0000\end{aligned}$ & $\begin{array}{rc}0.0229 & (0.0015) \\
p= & 0.0000\end{array}$ & $\begin{array}{cc}0.0418 & (0.0022) \\
p= & 0.0000\end{array}$ \\
\hline Region of Residence: North Central & $\begin{array}{rc}.0 .1810 & (0.0324) \\
p= & 0.0000\end{array}$ & $\begin{array}{rc}-0.1939 & (0.0440) \\
p= & 0.0000\end{array}$ & $\begin{array}{rc}-0.1490 & (0.0447) \\
p= & 0.0009\end{array}$ & $\begin{array}{rc}-0.0071 & (0.0860) \\
p & =0.9345\end{array}$ & $\begin{array}{rc}-0.1142 & (0.0173) \\
p= & 0.0000\end{array}$ & $\begin{array}{rc}-0.0997 & (0.0234) \\
p & =0.0000\end{array}$ \\
\hline Region of Residence: South & $\begin{array}{rc}-0.1811 & (0.0235) \\
p= & 0.0000\end{array}$ & $\begin{array}{rc}-0.1771 & (0.0396) \\
p= & 0.0000\end{array}$ & $\begin{array}{rc}-0.1710 & (0.0283) \\
p= & 0.0000\end{array}$ & $\begin{array}{rc}-0.1330 & (0.0508) \\
p= & 0.0089\end{array}$ & $\begin{array}{rc}-0.1484 & (0.0161) \\
p= & 0.0000\end{array}$ & $\begin{array}{rc}-0.0948 & (0.0219) \\
p= & 0.0000\end{array}$ \\
\hline Region of Residence: West & $\begin{array}{rc}-0.0444 & (0.0370) \\
p= & 0.2302\end{array}$ & $\begin{array}{rc}-0.0229 & (0.0561) \\
p= & 0.6838\end{array}$ & $\begin{array}{rc}-0.1136 & (0.0278) \\
p= & 0.0000\end{array}$ & $\begin{array}{rc}-0.0218 & (0.0469) \\
P & =0.6421\end{array}$ & $\begin{array}{rc}-0.0114 & (0.0194) \\
p= & 0.5556\end{array}$ & $\begin{array}{rr}-0.0395 & (0.0261) \\
p= & 0.1294\end{array}$ \\
\hline Local Unemployment Rate: 6-9\% & $\begin{array}{rc}-0.0658 & (0.0160) \\
p= & 0.0000\end{array}$ & $\begin{array}{rc}-0.0754 & (0.0230) \\
p= & 0.0010\end{array}$ & $\begin{array}{rc}-0.0588 & (0.0179) \\
p= & 0.0010\end{array}$ & $\begin{array}{rc}-0.0575 & (0.0276) \\
p= & 0.0373\end{array}$ & $\begin{array}{rc}-0.0879 & (0.0096) \\
p & =0.0000\end{array}$ & $\begin{array}{rr}-0.0393 & (0.0137) \\
p & =0.0041\end{array}$ \\
\hline Local Unemployment Rate: Over $9 \%$ & $\begin{array}{rc}-0.0983 & (0.0230) \\
p= & 0.0000\end{array}$ & $\begin{array}{rc}-0.1080 & (0.0385) \\
p= & 0.0050\end{array}$ & $\begin{array}{rc}-0.1516 & (0.0224) \\
P= & 0.0000\end{array}$ & $\begin{array}{rc}-0.1942 & (0.0331) \\
p= & 0.0000\end{array}$ & $\begin{array}{rc}-0.1332 & (0.0134) \\
p & =0.0000\end{array}$ & $\begin{array}{rc}-0.1038 & (0.0202) \\
p= & 0.0000\end{array}$ \\
\hline National Unemployment Rate: $6-9 \%$ & $\begin{array}{rc}-0.0102 & (0.0127) \\
p= & 0.4238\end{array}$ & $\begin{array}{rc}-0.0402 & (0.0219) \\
p= & 0.0665\end{array}$ & $\begin{array}{rc}-0.0287 & (0.0141) \\
p= & 0.0422\end{array}$ & $\begin{array}{cc}-0.0272 & (0.0223) \\
p= & 0.2221\end{array}$ & $\begin{array}{rc}-0.0169 & (0.0082) \\
p= & 0.0400\end{array}$ & $\begin{array}{rc}-0.0606 & (0.0115) \\
p & =0.0000\end{array}$ \\
\hline National Unemployment Rate: Over $9 \%$ & $\begin{array}{rc}-0.0165 & (0.0234) \\
p= & 0.4817\end{array}$ & $\begin{array}{rc}-0.1001 & (0.0386) \\
p= & 0.0095\end{array}$ & $\begin{array}{rc}-0.0278 & (0.0219) \\
p= & 0.2040\end{array}$ & $\begin{array}{rc}0.0293 & (0.0376) \\
p= & 0.4371\end{array}$ & $\begin{array}{rc}-0.0054 & (0.0132) \\
p= & 0.6819\end{array}$ & $\begin{array}{r}-0.0457(0.0211) \\
p=0.0300\end{array}$ \\
\hline Year & $\begin{array}{rc}-0.0045 & (0.0011) \\
p= & 0.0000\end{array}$ & $\begin{array}{r}-0.0015 \quad(0.0015) \\
p=0.3153\end{array}$ & $\begin{array}{cc}0.0115 & (0.0012) \\
p= & 0.0000\end{array}$ & $\begin{array}{rc}-0.0022 & (0.0018) \\
p= & 0.2096\end{array}$ & $\begin{array}{rc}0.0147 & (0.0007) \\
p= & 0.0000\end{array}$ & $\begin{array}{rc}0.0138 & (0.0009) \\
\mathrm{p}= & 0.0000\end{array}$ \\
\hline R-squared & $R^{2}=0.2617$ & $R^{2}=0.2589$ & $R^{2}=0.2576$ & $R^{2}=0.2203$ & $R^{2}=0.2712$ & $R^{2}=0.2873$ \\
\hline Number of Observations & 6956 & 3417 & 5236 & 2727 & 19499 & 11444 \\
\hline
\end{tabular}




\begin{tabular}{|c|c|c|c|c|c|}
\hline \multicolumn{6}{|c|}{$\begin{array}{c}\text { Table 11 } \\
\text { Contribution of Ability to White Collar Wage Determination } \\
\text { Modelled With and Without Human Capital } \\
\text { All Ability Measures Standardized by Age Cohort }\end{array}$} \\
\hline & \multicolumn{2}{|c|}{ Modelled With Background Variables Only } & \multicolumn{2}{|c|}{ Modelled With Human Capital } & \multirow[b]{2}{*}{ Obs. } \\
\hline Group & ÁFQT & $\mathrm{g}$ & AFQT & $\mathrm{g}$ & \\
\hline Black Females & $\begin{array}{c}0.194 \\
(-0.186) \\
p=-0.160\end{array}$ & $\begin{aligned} & 0.227 \\
&(-0.190) \\
& p=-0.165\end{aligned}$ & $\begin{array}{r}0.121 \\
(-0.175) \\
p=-0.176\end{array}$ & $\begin{array}{c}0.137 \\
(-0.178) \\
p=-0.180\end{array}$ & 6956 \\
\hline Change in $R^{2}=$ & 0.201 & 0.200 & 0.027 & 0.026 & \\
\hline Black Males & $\begin{array}{c}0.183 \\
(-0.152) \\
p=-0.130\end{array}$ & $\begin{array}{c}0.247 \\
(-0.161) \\
p=-0.137\end{array}$ & $\begin{array}{c}0.091 \\
(-0.181) \\
p=-0.160\end{array}$ & $\begin{aligned} & 0.133 \\
&(-0.184) \\
& p=-0.162\end{aligned}$ & 3417 \\
\hline Change in $R^{2}=$ & 0.198 & 0.206 & 0.015 & 0.019 & \\
\hline Hispanic Females & $p=-0.176$ & $\begin{array}{c}0.202 \\
(-0.189) \\
p=-0.196\end{array}$ & $\begin{array}{c}0.082 \\
(-0.140) \\
p=-0.166\end{array}$ & $\begin{array}{c}0.113 \\
(-0.154) \\
p=-0.178\end{array}$ & 5236 \\
\hline Change in $R^{2}=$ & 0.201 & 0.208 & 0.014 & 0.017 & \\
\hline Hispanic Males & $\begin{array}{c}0.122 \\
(-0.009) \\
p=-0.137\end{array}$ & $\begin{array}{c}0.226 \\
(-0.023) \\
p=-0.155\end{array}$ & $\begin{array}{c}0.055 \\
(0.007) \\
p=-0.114\end{array}$ & $\begin{array}{c}0.119 \\
(-0.002) \\
p=-0.127\end{array}$ & 2727 \\
\hline Change in $R^{2}=$ & 0.156 & 0.168 & 0.005 & 0.009 & \\
\hline White Females & $\begin{array}{c}0.174 \\
(-0.135) \\
p=-0.153\end{array}$ & $\begin{array}{c}0.222 \\
(-0.143) \\
p=-0.163\end{array}$ & $\begin{array}{c}0.082 \\
(-0.113) \\
p=-0.153\end{array}$ & $\begin{array}{c}0.100 \\
(-0.117) \\
p=-0.158\end{array}$ & 19499 \\
\hline Change in $R^{2}=$ & 0.221 & 0.220 & 0.010 & 0.009 & \\
\hline White Males & $\begin{array}{c}0.160 \\
(-0.072) \\
p=-0.065\end{array}$ & $\begin{array}{c}0.258 \\
(-0.089) \\
p=-0.075\end{array}$ & $\begin{array}{c}0.066 \\
(-0.073) \\
p=-0.088\end{array}$ & $\begin{array}{c}0.125 \\
(-0.081) \\
p=-0.090\end{array}$ & 11444 \\
\hline Change in $R^{2}=$ & 0.223 & 0.235 & 0.005 & 0.009 & \\
\hline
\end{tabular}




\begin{tabular}{|c|c|c|c|c|c|c|}
\hline \multirow{3}{*}{\begin{tabular}{|l} 
Variable \\
Factor Loading
\end{tabular}} & \multicolumn{4}{|c|}{$\begin{array}{c}\text { TABLE 12: SIMULTANEOUS EQUATION MODEL } \\
\text { DETERMINANTS OF OCCUPATION CHOICE AND WAGES } \\
\text { OCCUPATION CHOICE: WHITE COLLAR VS. BLUE COLLAR } \\
\text { Random Effects Probit Equation Using Stacked, Person-Year Observations } \\
1 \text { Common Unobserved Factor Estimated Non-Parametrically } \\
\text { Dependent Varlable: White Collar } \\
\text { Standard Errors in Parentheses }\end{array}$} & \multirow[b]{2}{*}{ White Females } & \multirow[b]{2}{*}{ White Males } \\
\hline & Black Females & Black Males & Hispanic Females & Hispanic Males & & \\
\hline & $\begin{array}{r}1.4400 \quad(0.0348) \\
p=0.0000\end{array}$ & $\begin{array}{c}0.5961 \quad(0.0393) \\
p=0.0000\end{array}$ & $\begin{array}{r}1.4669 \quad(0.0462) \\
p=0.0000\end{array}$ & $\begin{array}{r}0.7932 \quad(0.0331) \\
p=0.0000\end{array}$ & $\begin{array}{c}1.2626 \quad(0.0202) \\
p=0.0000\end{array}$ & $\begin{array}{r}0.3163 \quad(0.0136) \\
p=0.0000\end{array}$ \\
\hline Wage White Collar - Wage Blue Collar & $\begin{array}{r}0.7031 \quad(0.0736) \\
p=0.0000\end{array}$ & $\begin{array}{c}1.9452 \quad(0.0930) \\
p=0.0000\end{array}$ & $\begin{array}{r}0.8667 \quad(0.0890) \\
p=0.0000\end{array}$ & $\begin{array}{c}1.1529 \quad(0.0988) \\
p=0.0000\end{array}$ & $\begin{array}{r}0.7155 \quad(0.0463) \\
p=0.0000\end{array}$ & $\begin{array}{r}0.9792 \quad(0.0483) \\
p=0.0000\end{array}$ \\
\hline 1st Principal Component (g) & $\begin{array}{r}0.5619 \quad(0.0239) \\
p=0.0000\end{array}$ & $\begin{array}{c}0.3798 \quad(0.0299) \\
p=0.0000\end{array}$ & $\begin{array}{c}0.2807 \quad(0.0325) \\
p=0.0000\end{array}$ & $\begin{array}{c}0.3106 \quad(0.0319) \\
p=0.0000\end{array}$ & $\begin{array}{r}0.2495 \quad(0.0139) \\
p=0.0000\end{array}$ & $\begin{array}{r}0.326+\underset{p=0.0000}{(0.0128)} \\
\end{array}$ \\
\hline 2nd Principal Component & $\begin{array}{r}-0.0889 \quad(0.0183) \\
p=0.0000\end{array}$ & $\begin{array}{c}0.1817 \quad(0.0233) \\
p=0.0000\end{array}$ & $\begin{array}{r}0.1484 \quad(0.0279) \\
p=0.0000\end{array}$ & $\begin{array}{r}0.1421 \quad(0.0200) \\
p=0.0000\end{array}$ & $\begin{array}{r}0.1782 \quad(0.0103) \\
p=0.0000\end{array}$ & $\begin{array}{r}0.2033 \quad(0.0089) \\
p=0.0000\end{array}$ \\
\hline 3rd Principal Component & $\begin{array}{r}-0.0040 \quad(0.0170) \\
p=0.8162\end{array}$ & $\begin{array}{r}-0.0294 \quad(0.0219) \\
p=0.1792\end{array}$ & $\begin{array}{r}-0.0620 \quad(0.0228) \\
p=0.0065\end{array}$ & $\begin{array}{c}-0.1431 \quad(0.0233) \\
p=0.0000\end{array}$ & $\begin{array}{c}-0.0381 \quad(0.0115) \\
p=0.0009\end{array}$ & $\begin{array}{c}-0.0902 \quad(0.0087) \\
p=0.0000\end{array}$ \\
\hline 4th Principal Component & $\begin{array}{r}0.0094 \quad(0.0187) \\
p=0.6137\end{array}$ & $\begin{array}{r}-0.0760 \quad(0.0230) \\
p=0.0010\end{array}$ & $\begin{array}{r}0.0716 \quad(0.0247) \\
p=0.0038\end{array}$ & $\begin{array}{r}-0.1041 \quad(0.0195) \\
p=0.0000\end{array}$ & $\begin{array}{c}-0.0040 \quad(0.0101) \\
p=0.6908\end{array}$ & $\begin{array}{r}-0.0953 \quad(0.0088) \\
p=0.0000\end{array}$ \\
\hline Sth Principal Component & $\begin{array}{r}-0.0480 \quad(0.0154) \\
p=0.0018\end{array}$ & $\begin{array}{c}0.0155 \quad(0.0224) \\
p=0.4873\end{array}$ & $\begin{array}{r}0.0218 \quad(0.0234) \\
p=0.3507\end{array}$ & $\begin{array}{r}-0.0658 \quad(0.0205) \\
p=0.0013\end{array}$ & $\begin{array}{r}-0.0444 \quad(0.0101) \\
p=0.0000\end{array}$ & $\begin{array}{r}-0.0365 \quad(0.0077) \\
p=0.0000\end{array}$ \\
\hline 6th Principal Component & $\begin{array}{r}-0.1182 \quad(0.0169) \\
p=0.0000\end{array}$ & $\begin{array}{c}0.0327 \quad(0.0228) \\
p=0.1510\end{array}$ & $\begin{array}{c}.0 .0241 \quad(0.0232) \\
p=0.2998\end{array}$ & $\begin{array}{c}.0 .0371 \quad(0.0195) \\
p=0.0566\end{array}$ & $\begin{array}{r}0.0069 \quad(0.0100) \\
p=0.4930\end{array}$ & $\begin{array}{r}-0.0188 \quad(0.0082) \\
p=0.0214\end{array}$ \\
\hline 7th Principal Component & $\begin{array}{r}0.0112 \quad(0.0178) \\
p=0.5296\end{array}$ & $\begin{array}{c}0.0741 \quad(0.0224) \\
p=0.0010\end{array}$ & $\begin{array}{c}-0.0659 \quad(0.0232) \\
p=0.0045\end{array}$ & $\begin{array}{c}0.1305 \quad(0.0205) \\
p=0.0000\end{array}$ & $\begin{array}{r}-0.0232 \quad(0.0100) \\
p=0.0204\end{array}$ & $\begin{array}{r}-0.0657 \quad(0.0079) \\
p=0.0000\end{array}$ \\
\hline 8th Principal Component & $\begin{array}{r}-0.0188 \quad(0.0166) \\
p=0.2573\end{array}$ & $\begin{array}{c}0.0775 \quad(0.0242) \\
p=0.0014\end{array}$ & $\begin{array}{r}-0.1282(0.0243) \\
p=0.0000\end{array}$ & $\begin{array}{r}0.0430 \quad(0.0207) \\
p=0.0378\end{array}$ & $\begin{array}{c}0.0227 \quad(0.0100) \\
p=0.0229\end{array}$ & $\begin{array}{c}0.0423 \quad(0.0081) \\
p=0.0000\end{array}$ \\
\hline 9th Principal Component & $\begin{array}{c}0.0307 \quad(0.0167) \\
p=0.0658\end{array}$ & $\begin{array}{r}0.0283 \quad(0.0238) \\
p=0.2332\end{array}$ & $\begin{array}{c}-0.0070 \quad(0.0231) \\
p=0.7604\end{array}$ & $\begin{array}{c}0.0207 \quad(0.0198) \\
p=0.2955\end{array}$ & $\begin{array}{r}-0.0645 \quad(0.0100) \\
p=0.0000\end{array}$ & $\begin{array}{r}-0.0451 \quad(0.0077) \\
p=0.0000\end{array}$ \\
\hline 10th Principal Component & $\begin{array}{r}0.0124 \quad(0.0171) \\
p=0.4677\end{array}$ & $\begin{array}{r}-0.0672 \quad(0.0225) \\
p=0.0028\end{array}$ & $\begin{array}{r}-0.0618(0.0231) \\
p=0.0076\end{array}$ & $\begin{array}{r}-0.0223 \quad(0.0195) \\
p=0.2527\end{array}$ & $\begin{array}{r}0.0264 \quad(0.0094) \\
p=0.0052\end{array}$ & $\begin{array}{c}0.0294 \quad(0.0075) \\
p=0.0001\end{array}$ \\
\hline Grades Completed & $\begin{array}{r}0.1631 \quad(0.0104) \\
p=0.0000\end{array}$ & $\begin{array}{r}0.2042 \quad(0.0146) \\
p=0.0000\end{array}$ & $\begin{array}{r}0.1413 \quad(0.0124) \\
p=0.0000\end{array}$ & $\begin{array}{c}0.1729 \quad(0.0114) \\
p=0.0000\end{array}$ & $\begin{array}{r}0.2209(0.0055) \\
p=0.0000\end{array}$ & $\begin{array}{r}0.1988 \quad(0.0046) \\
p=0.0000\end{array}$ \\
\hline Potential Experience & $\begin{array}{r}-0.0419 \quad(0.0063) \\
p=0.0000\end{array}$ & $\begin{array}{c}-0.0101 \quad(0.0081) \\
p=0.2148\end{array}$ & $\begin{array}{r}-0.0498 \quad(0.0086) \\
p=0.0000\end{array}$ & $\begin{array}{r}-0.0121 \quad(0.0074) \\
p=0.1027\end{array}$ & $\begin{array}{r}0.0043 \quad(0.0036) \\
p=0.2354\end{array}$ & $\begin{array}{r}-0.0036 \quad(0.0029) \\
p=0.2268\end{array}$ \\
\hline Mother White Collar & $\begin{array}{r}0.2153(0.0371) \\
p=0.0000\end{array}$ & $\begin{array}{r}0.1729 \quad(0.0336) \\
p=0.0000\end{array}$ & $\begin{array}{r}-0.1024 \quad(0.0600) \\
p=0.0876\end{array}$ & $\begin{array}{r}0.1169 \quad(0.0347) \\
p=0.0008\end{array}$ & $\begin{array}{r}0.0614 \quad(0.0160) \\
p=0.0001\end{array}$ & $\begin{array}{r}0.0689(0.0112) \\
p=0.0000\end{array}$ \\
\hline Father White Collar & $\begin{array}{c}0.1639(0.0415) \\
p=0.0001\end{array}$ & $\begin{array}{r}0.2786(0.0496) \\
\mathrm{p}=0.0000\end{array}$ & $\begin{array}{r}0.2442 \quad(0.0512) \\
p=0.0000\end{array}$ & $\begin{array}{r}-0.0518 \quad(0.0348) \\
p=0.1367\end{array}$ & $\begin{array}{r}.0 .0063 \quad(0.0157) \\
p=0.6857\end{array}$ & $\begin{array}{r}0.2084(0.0114) \\
p=0.0000\end{array}$ \\
\hline Factor 1, Support Point 1: & $0.0000 \quad(0.0000)$ & $0.0000 \quad(0.0000)$ & $0.0000 \quad(0.0000)$ & $0.0000 \quad(0.0000)$ & $0.0000 \quad(0.0000)$ & $0.0000 \quad(0.0000)$ \\
\hline Factor 1, Prob Mass for Point l: & $0.5627(0.0160)$ & $0.5852(0.0163)$ & $0.5117(0.0203)$ & $0.5482 \quad(0.0206)$ & $0.5354(0.0105)$ & $0.5087(0.0107)$ \\
\hline Factor 1, Support Point 2 : & $1.0000(0.0000)$ & $1.0000 \quad(0.0000)$ & $1.0000 \quad(0.0000)$ & $1.0000 \quad(0.0000)$ & $1.0000 \quad(0.0000)$ & $1.0000 \quad(0.0000)$ \\
\hline Factor 1, Prob. Mass for Point 2 & $0.4373(0.0160)$ & $0.4148 \quad(0.0163)$ & $0.4883 \quad(0.0203)$ & $0.4518 \quad(0.0206)$ & $0.4646(0.0105)$ & $0.4913(0.0107)$ \\
\hline Negative Log-Likelihood & 13160.7813 & 14238.6719 & 8621.8594 & 10066.4063 & 35880.9375 & 36143.1563 \\
\hline Number of Respondents & 1396 & 1451 & 884 & 881 & 3338 & 3368 \\
\hline
\end{tabular}

1. Table updared on December 12, 1997

2. Sample inciudes all valid person-year observations who are both employed and not in school.

3. Principal Components standardized to have mean 0 and inter-quarile range 1.

4. Incercept and year inclujed in model but not reported.

4. Incercept axd year included in model but not reported.

All coefficients for blue collar except for wages have been constrainted to equal zero. These normalizations are necessary for identification.

6. The reponted coefficients are for the stale index function for while coller. The only coefficient effecting the bive collar index function that has not been normalized to zero is blue collar wage 


\begin{tabular}{|c|c|}
\hline \multicolumn{2}{|c|}{$\begin{array}{c}\text { TABLE: } 13 \text { WITHIN SAMPLE PREDICTION RATES FOR OCCUPATION CHOICE } \\
\text { Simultaneous Equation Model } \\
\text { Random Effect Probit Equation Using Stacked, Person-Year Observations } \\
\text { Dependent Variable: White Collar } \\
\text { Cutoff Value is Sample Fraction Selecting into a White Collar Occupation }\end{array}$} \\
\hline $\begin{array}{c}\text { Black Females } \\
\text { Cutoff Value: } 0.56\end{array}$ & \\
\hline $\begin{array}{l}\text { Fraction of blue collar workers correctly predicted within sample: } \\
\text { Fraction of white collar workers correctly predicted within sample: } \\
\text { Equal weights within sample prediction rate: } \\
\text { Population weights within-sample prediction rate: }\end{array}$ & $\begin{array}{l}0.76 \\
0.60 \\
0.68 \\
0.67\end{array}$ \\
\hline \multicolumn{2}{|l|}{$\begin{array}{c}\text { Black Males } \\
\text { Cutoff Value: } 0.25\end{array}$} \\
\hline $\begin{array}{l}\text { Fraction of blue collar workers correctly predicted within sample: } \\
\text { Fraction of white collar workers correctly predicted within sample: } \\
\text { Equal weights within sample prediction rate: } \\
\text { Population weights within-sample prediction rate: }\end{array}$ & $\begin{array}{l}0.76 \\
0.69 \\
0.72 \\
0.74\end{array}$ \\
\hline \multicolumn{2}{|l|}{$\begin{array}{l}\text { Hispanic Females } \\
\text { Cutoff Value: } 0.65\end{array}$} \\
\hline $\begin{array}{l}\text { Fraction of blue collar workers correctly predicted within sample: } \\
\text { Fraction of white collar workers correctly predicted within sample: } \\
\text { Equal weights within sample prediction rate: } \\
\text { Population weights within-sample prediction rate: }\end{array}$ & $\begin{array}{l}0.70 \\
0.64 \\
0.67 \\
0.66\end{array}$ \\
\hline \multicolumn{2}{|l|}{$\begin{array}{c}\text { Hispanic Males } \\
\text { Cutoff Value: } 0.30\end{array}$} \\
\hline $\begin{array}{l}\text { Fraction of blue collar workers correctly predicted within sample: } \\
\text { Fraction of white collar workers correctly predicted within sample: } \\
\text { Equal weights within sample prediction rate: } \\
\text { Population weights within-sample prediction rate: }\end{array}$ & $\begin{array}{l}0.72 \\
0.70 \\
0.71 \\
0.71\end{array}$ \\
\hline \multicolumn{2}{|l|}{$\begin{array}{c}\text { White Females } \\
\text { Cutoff Value: } 0.63\end{array}$} \\
\hline $\begin{array}{l}\text { Fraction of blue collar workers correctly predicted within sample: } \\
\text { Fraction of white collar workers correctly predicted within sample: } \\
\text { Equal weights within sample prediction rate: } \\
\text { Population weights within-sample prediction rate: }\end{array}$ & $\begin{array}{l}0.77 \\
0.55 \\
0.66 \\
0.63\end{array}$ \\
\hline \multicolumn{2}{|l|}{$\begin{array}{c}\text { White Males } \\
\text { Cutoff Value: } 0.35\end{array}$} \\
\hline $\begin{array}{l}\text { Fraction of blue collar workers correctly predicted within sample: } \\
\text { Fraction of white collar workers correctly predicted within sample: } \\
\text { Equal weights within sample prediction rate: } \\
\text { Population weights within-sample prediction rate: }\end{array}$ & $\begin{array}{l}0.78 \\
0.70 \\
0.74 \\
0.75\end{array}$ \\
\hline
\end{tabular}

1. Table updated on December 12,1997

2. Sample includes all valid person-year observations who are both employed and not in school.

3. Specification includes the ten principal component scores, grades completed, potential experience, mothers occupation category, fathers occupation category, and the difference in estimated white collar versus blue collar wages.

4. The equal weights within-sample prediction rate is the simple blue collar and the white collar prediction rates. The population weighted rate of correct predictions is the unweighted rate in the population 


\begin{tabular}{|c|c|c|c|c|c|c|}
\hline \multicolumn{7}{|c|}{$\begin{array}{c}\text { TABLE 14: SIMULTANEOUS EQUATION MODEL } \\
\text { DETERMINANTS OF OCCUPATION CHOICE AND WAGES } \\
\text { WAGE REGRESSIONS FOR BLUE COLLAR } \\
\text { Regression Using Stacked, Person-Year Observations } \\
\text { 1 Common Unobserved Factor Estimated Non-Parametrically } \\
\text { Dependent Variable: Log Wages } \\
\text { Standard Errors in Parentheses }\end{array}$} \\
\hline Variable & Black Females & Black Males & Hispanic Females & Hispanic Males & White Females & White Males \\
\hline Factor Loading & $\begin{array}{c}-0.1692(0.0214) \\
p=0.0000\end{array}$ & $\begin{array}{r}0.3855(0.0066) \\
p=0.0000\end{array}$ & $\begin{array}{r}-0.1953 \quad(0.0335) \\
p=0.0000\end{array}$ & $\begin{array}{r}0.3430 \quad(0.0091) \\
p=0.0000\end{array}$ & $\begin{array}{c}-0.0566 \quad(0.0161) \\
p=0.0004\end{array}$ & $\begin{array}{r}0.4209 \quad(0.0046) \\
p=0.0000\end{array}$ \\
\hline Intercept & $\begin{array}{r}1.5740 \quad(0.1910) \\
p=0.0000\end{array}$ & $\begin{array}{r}1.6228 \quad(0.1322) \\
p=0.0000\end{array}$ & $\begin{array}{r}2.4589(0.3015) \\
p=0.0000\end{array}$ & $\begin{array}{r}1.5435 \quad(0.1653) \\
p=0.0000\end{array}$ & $\begin{array}{r}1.7175 \quad(0.1531) \\
p=0.0000\end{array}$ & $\begin{array}{c}1.1581 \quad(0.0886) \\
p=0.0000\end{array}$ \\
\hline 1st Principal Component (g) & $\begin{array}{r}0.0660 \quad(0.0088) \\
p=0.0000\end{array}$ & $\begin{array}{r}0.0471 \quad(0.0061) \\
p=0.0000\end{array}$ & $\begin{array}{r}0.0144 \quad(0.0140) \\
p=0.3046\end{array}$ & $\begin{array}{r}0.0897 \quad(0.0087) \\
p=0.0000\end{array}$ & $\begin{array}{r}0.0293 \quad(0.0061) \\
p=0.0000\end{array}$ & $\begin{array}{r}0.0378 \quad(0.0039) \\
p=0.0000\end{array}$ \\
\hline 2nd Principal Component & $\begin{array}{r}-0.0120 \quad(0.0061) \\
p=0.0489\end{array}$ & $\begin{array}{r}-0.0052 \quad(0.0043) \\
p=0.2228\end{array}$ & $\begin{array}{c}-0.0237 \quad(0.0113) \\
p=0.0353\end{array}$ & $\begin{array}{r}0.0096 \quad(0.0050) \\
p=0.0537\end{array}$ & $\begin{array}{r}0.0392 \quad(0.0049) \\
p=0.0000\end{array}$ & $\begin{array}{r}-0.0385 \quad(0.0033) \\
p=0.0000\end{array}$ \\
\hline 3rd Principal Component & $\begin{array}{r}-0.0070 \quad(0.0062) \\
p=0.2613\end{array}$ & $\begin{array}{r}0.0371 \quad(0.0047) \\
p=0.0000\end{array}$ & $\begin{array}{r}0.0008 \quad(0.0092) \\
p=0.9336\end{array}$ & $\begin{array}{r}0.1006 \quad(0.0067) \\
p=0.0000\end{array}$ & $\begin{array}{r}0.0483 \quad(0.0048) \\
p=0.0000\end{array}$ & $\begin{array}{r}0.0889 \quad(0.0032) \\
p=0.0000\end{array}$ \\
\hline 4th Principal Component & $\begin{array}{r}0.0277 \quad(0.0065) \\
p=0.0000\end{array}$ & $\begin{array}{r}0.0336 \quad(0.0048) \\
p=0.0000\end{array}$ & $\begin{array}{c}-0.0053 \quad(0.0108) \\
p=0.6211\end{array}$ & $\begin{array}{r}0.0459(0.0051) \\
p=0.0000\end{array}$ & $\begin{array}{r}0.0493(0.0041) \\
p=0.0000\end{array}$ & $\begin{array}{r}-0.0158 \quad(0.0028) \\
p=0.0000\end{array}$ \\
\hline 5th Principal Component & $\begin{array}{c}-0.0156 \quad(0.0059) \\
p=0.0081\end{array}$ & $\begin{array}{r}0.0348 \quad(0.0045) \\
p=0.0000\end{array}$ & $\begin{array}{r}-0.0569 \quad(0.0093) \\
p=0.0000\end{array}$ & $\begin{array}{r}0.0561 \quad(0.0054) \\
p=0.0000\end{array}$ & $\begin{array}{r}-0.0201 \quad(0.0043) \\
p=0.0000\end{array}$ & $\begin{array}{c}0.0642 \quad(0.0028) \\
p=0.0000\end{array}$ \\
\hline 6th Principal Component & $\begin{array}{r}-0.0021 \quad(0.0059) \\
p=0.7269\end{array}$ & $\begin{array}{r}-0.0114 \quad(0.0045) \\
p=0.0109\end{array}$ & $\begin{array}{r}-0.0170 \quad(0.0098) \\
p=0.0821\end{array}$ & $\begin{array}{c}0.0064 \quad(0.0051) \\
p=0.2089\end{array}$ & $\begin{array}{r}-0.0266 \quad(0.0045) \\
p=0.0000\end{array}$ & $\begin{array}{r}0.0084 \quad(0.0029) \\
p=0.0032\end{array}$ \\
\hline 7th Principal Component & $\begin{array}{r}-0.0230 \quad(0.0059) \\
p=0.0001\end{array}$ & $\begin{array}{r}-0.0008 \quad(0.0044) \\
p=0.8573\end{array}$ & $\begin{array}{r}0.0106 \quad(0.0102) \\
p=0.3013\end{array}$ & $\begin{array}{r}0.0578 \quad(0.0056) \\
p=0.0000\end{array}$ & $\begin{array}{r}0.0259 \quad(0.0044) \\
p=0.0000\end{array}$ & $\begin{array}{r}-0.0049 \quad(0.0030) \\
p=0.1025\end{array}$ \\
\hline 8th Principal Component & $\begin{array}{r}-0.0202 \quad(0.0060) \\
p=0.0007\end{array}$ & $\begin{array}{r}0.0397(0.0045) \\
p=0.0000\end{array}$ & $\begin{array}{r}-0.0379 \quad(0.0093) \\
p=0.0001\end{array}$ & $\begin{array}{r}0.0118 \quad(0.0055) \\
p=0.0320\end{array}$ & $\begin{array}{r}-0.0084 \quad(0.0043) \\
p=0.0472\end{array}$ & $\begin{array}{r}0.0074 \quad(0.0028) \\
\mathrm{p}=0.0078\end{array}$ \\
\hline 9th Principal Component & $\begin{array}{c}-0.0229 \quad(0.0062) \\
p=0.0002\end{array}$ & $\begin{array}{r}-0.0054 \quad(0.0048) \\
p=0.2543\end{array}$ & $\begin{array}{r}0.0113 \quad(0.0096) \\
p=0.2371\end{array}$ & $\begin{array}{r}-0.0015 \quad(0.0051) \\
p=0.7727\end{array}$ & $\begin{array}{r}-0.0056 \quad(0.0041) \\
p=0.1727\end{array}$ & $\begin{array}{c}-0.0019 \quad(0.0025) \\
p=0.4481\end{array}$ \\
\hline 10th Principal Component & $\begin{array}{r}0.0041 \quad(0.0056) \\
p=0.4570\end{array}$ & $\begin{array}{r}-0.0025 \quad(0.0043) \\
p=0.5596\end{array}$ & $\begin{array}{r}-0.0133 \quad(0.0102) \\
p=0.1918\end{array}$ & $\begin{array}{r}0.0289 \quad(0.0050) \\
p=0.0000\end{array}$ & $\begin{array}{r}-0.0067 \quad(0.0043) \\
p=0.1171\end{array}$ & $\begin{array}{r}-0.0070 \quad(0.0028) \\
p=0.0132\end{array}$ \\
\hline Grades Completed & $\begin{array}{r}0.0434 \quad(0.0037) \\
p=0.0000\end{array}$ & $\begin{array}{r}0.0544 \quad(0.0028) \\
p=0.0000\end{array}$ & $\begin{array}{r}0.0325 \quad(0.0056) \\
p=0.0000\end{array}$ & $\begin{array}{r}0.0479(0.0030) \\
p=0.0000\end{array}$ & $\begin{array}{r}0.0452(0.0031) \\
p=0.0000\end{array}$ & $\begin{array}{c}0.0501 \quad(0.0017) \\
p=0.0000\end{array}$ \\
\hline Potential Experience & $\begin{array}{r}0.0173(0.0020) \\
p=0.0000\end{array}$ & $\begin{array}{r}0.0259 \quad(0.0015) \\
p=0.0000\end{array}$ & $\begin{array}{r}0.0284 \quad(0.0035) \\
p=0.0000\end{array}$ & $\begin{array}{r}0.0398 \quad(0.0019) \\
p=0.0000\end{array}$ & $\begin{array}{r}0.0262(0.0016) \\
p=0.0000\end{array}$ & $\begin{array}{c}0.0350(0.0011) \\
p=0.0000\end{array}$ \\
\hline Region of Residence: North Central & $\begin{array}{r}-0.0771 \quad(0.0159) \\
p=0.0000\end{array}$ & $\begin{array}{r}-0.0495(0.0097) \\
p=0.0000\end{array}$ & $\begin{array}{r}-0.1609 \quad(0.0313) \\
p=0.0000\end{array}$ & $\begin{array}{r}-0.0817 \quad(0.0164) \\
\mathrm{p}=0.0000\end{array}$ & $\begin{array}{r}-0.1272 \quad(0.0093) \\
p=0.0000\end{array}$ & $\begin{array}{r}.0 .0838 \quad(0.0063) \\
p=0.0000\end{array}$ \\
\hline Region of Residence: South & $\begin{array}{r}-0.0874 \quad(0.0134) \\
p=0.0000\end{array}$ & $\begin{array}{r}-0.0475 \quad(0.0082) \\
p=0.0000\end{array}$ & $\begin{array}{r}-0.1469 \quad(0.0268) \\
p=0.0000\end{array}$ & $\begin{array}{r}-0.1551 \quad(0.0123) \\
p=0.0000\end{array}$ & $\begin{array}{r}-0.1121 \quad(0.0096) \\
p=0.0000\end{array}$ & $\begin{array}{r}-0.0589 \quad(0.0066) \\
p=0.0000\end{array}$ \\
\hline Region of Residence: West & $\begin{array}{r}-0.0541 \quad(0.0218) \\
p=0.0131\end{array}$ & $\begin{array}{r}0.0690 \quad(0.0121) \\
p=0.0000\end{array}$ & $\begin{array}{r}0.0423 \quad(0.0246) \\
p=0.0860\end{array}$ & $\begin{array}{r}-0.0082 \quad(0.0112) \\
\mathrm{p}=0.4643\end{array}$ & $\begin{array}{r}-0.0712 \quad(0.0109) \\
p=0.0000\end{array}$ & $\begin{array}{r}0.0149 \quad(0.0072) \\
p=0.0388\end{array}$ \\
\hline Local Unemployment Rate: $6 \%-9 \%$ & $\begin{array}{c}0.0008 \quad(0.0147) \\
p=0.9546\end{array}$ & $\begin{array}{r}-0.0287 \quad(0.0102) \\
p=0.0048\end{array}$ & $\begin{array}{r}-0.0218 \quad(0.0253) \\
p=0.3891\end{array}$ & $\begin{array}{r}-0.0656 \quad(0.0127) \\
\mathrm{p}=0.0000\end{array}$ & $\begin{array}{r}-0.0391 \quad(0.0110) \\
p=0.0004\end{array}$ & $\begin{array}{r}-0.0372(0.0069) \\
p=0.0000\end{array}$ \\
\hline Local Unemployment Rate: Over $9 \%$ & $\begin{array}{c}-0.0414 \quad(0.0162) \\
p=0.0108\end{array}$ & $\begin{array}{r}-0.0380 \quad(0.0120) \\
p=0.0016\end{array}$ & $\begin{array}{r}-0.0815 \quad(0.0235) \\
p=0.0005\end{array}$ & $\begin{array}{r}-0.1420 \quad(0.0121) \\
p=0.0000\end{array}$ & $\begin{array}{r}-0.0631 \quad(0.0108) \\
p=0.0000\end{array}$ & $\begin{array}{r}-0.0749 \quad(0.0068) \\
p=0.0000\end{array}$ \\
\hline National Unemployment Rate: $6 \%-9 \%$ & $\begin{array}{r}-0.0263 \quad(0.0180) \\
p=0.1449\end{array}$ & $\begin{array}{r}-0.0305 \quad(0.0116) \\
p=0.0086\end{array}$ & $\begin{array}{r}-0.0369 \quad(0.0275) \\
p=0.1798\end{array}$ & $\begin{array}{r}-0.0087 \quad(0.0149) \\
p=0.5599\end{array}$ & $\begin{array}{r}0.0046 \quad(0.0131) \\
p=0.7254\end{array}$ & $\begin{array}{r}-0.0266 \quad(0.0077) \\
p=0.0006\end{array}$ \\
\hline National Unemployment Rate: Over $9 \%$ & $\begin{array}{r}-0.0358 \quad(0.0276) \\
p=0.1952\end{array}$ & $\begin{array}{r}-0.0797 \quad(0.0172) \\
p=0.0000\end{array}$ & $\begin{array}{r}-0.0380 \quad(0.0423) \\
p=0.3697\end{array}$ & $\begin{array}{r}-0.0126 \quad(0.0227) \\
p=0.5801\end{array}$ & $\begin{array}{r}0.0050 \quad(0.0189) \\
p=0.7926\end{array}$ & $\begin{array}{r}-0.0358 \quad(0.0107) \\
p=0.0008\end{array}$ \\
\hline Year & $\begin{array}{r}-0.0061 \quad(0.0025) \\
p=0.0124\end{array}$ & $\begin{array}{r}-0.0084 \quad(0.0018) \\
p=0.0000\end{array}$ & $\begin{array}{r}-0.0162 \quad(0.0040) \\
p=0.0001\end{array}$ & $\begin{array}{r}-0.0052(0.0022) \\
p=0.0184\end{array}$ & $\begin{array}{r}-0.0092 \quad(0.0020) \\
p=0.0000\end{array}$ & $\begin{array}{r}-0.0018 \quad(0.0012) \\
p=0.1357\end{array}$ \\
\hline R-squared & .08 & .12 & .06 & .21 & .09 & 18 \\
\hline
\end{tabular}

1. Tahle updated on December 12. 1997

2. Excluded category for region of residence is northeast. Excluded calegory for local and nalimal unemployment rale is less than $6 \%$. 


\begin{tabular}{|c|c|c|c|c|c|c|}
\hline \multicolumn{7}{|c|}{$\begin{array}{c}\text { TABLE 15: SIMULTANEOUS EQUATION MODEL } \\
\text { DETERMINANTS OF OCCUPATION CHOICE AND WAGES } \\
\text { WAGE REGRESSIONS FOR WHITE COLLAR } \\
\text { Regression Using Stacked, Person-Year Observations } \\
\text { 1 Common Unobserved Factor Estimated Non-Parametrically } \\
\text { Dependent Variable: Log Wages } \\
\text { Standard Errors in Parentheses }\end{array}$} \\
\hline Variable & Black Females & Black Males & Hispanic Females & Hispanic Males & White Females & White Males \\
\hline Factor Loading & $\begin{array}{c}0.3667 \begin{array}{c}(0.0104) \\
p=0.0000\end{array}\end{array}$ & $\begin{array}{c}0.5607 \quad(0.0156) \\
p=0.0000\end{array}$ & $\begin{array}{c}0.3558(0.0116) \\
p=0.0000\end{array}$ & $\begin{array}{c}0.6107 \quad(0.0194) \\
p=0.0000\end{array}$ & $\begin{array}{c}0.4277(0.0061) \\
\mathrm{p}=0.0000\end{array}$ & $\begin{array}{r}0.5188 \quad(0.0071) \\
p=0.0000\end{array}$ \\
\hline Intercept & $\begin{array}{c}0.0114 \quad(0.1625) \\
p=0.9441\end{array}$ & $\begin{array}{r}-1.1524 \quad(0.2733) \\
p=0.0000\end{array}$ & $\begin{array}{r}-1.1235 \quad(0.1807) \\
p=0.0000\end{array}$ & $\begin{array}{r}-0.6300 \quad(0.2991) \\
p=0.0352\end{array}$ & $\begin{array}{r}-1.1489 \quad(0.0927) \\
p=0.0000\end{array}$ & $\begin{array}{r}-1.7993 \quad(0.1322) \\
p=0.0000\end{array}$ \\
\hline 1st Principal Component (g) & $\begin{array}{r}0.2169(0.0059) \\
p=0.0000\end{array}$ & $\begin{array}{r}0.1955 \quad(0.0120) \\
p=0.0000\end{array}$ & $\begin{array}{r}0.1505 \quad(0.0067) \\
p=0.0000\end{array}$ & $\begin{array}{r}0.1888 \quad(0.0159) \\
p=0.0000\end{array}$ & $\begin{array}{r}0.1221 \quad(0.0044) \\
p=0.0000\end{array}$ & $\begin{array}{r}0.1189(0.0080) \\
p=0.0000\end{array}$ \\
\hline 2nd Principal Component & $\begin{array}{r}-0.0455 \quad(0.0042) \\
p=0.0000\end{array}$ & $\begin{array}{r}0.0416 \quad(0.0098) \\
\mathrm{p}=0.0000\end{array}$ & $\begin{array}{r}0.0512(0.0065) \\
p=0.0000\end{array}$ & $\begin{array}{r}0.0776 \quad(0.0104) \\
p=0.0000\end{array}$ & $\begin{array}{r}0.0661 \quad(0.0029) \\
p=0.0000\end{array}$ & $\begin{array}{r}0.0399(0.0049) \\
p=0.0000\end{array}$ \\
\hline 3rd Principal Component & $\begin{array}{c}0.0169(0.0039) \\
p=0.0000\end{array}$ & $\begin{array}{c}0.0015 \quad(0.0087) \\
p=0.8603\end{array}$ & $\begin{array}{c}0.0202 \quad(0.0054) \\
p=0.0002\end{array}$ & $\begin{array}{c}0.0326 \quad(0.0112) \\
p=0.0036\end{array}$ & $\begin{array}{r}-0.0330 \quad(0.0033) \\
p=0.0000\end{array}$ & $\begin{array}{r}0.0625 \quad(0.0052) \\
p=0.0000\end{array}$ \\
\hline 4th Principal Component & $\begin{array}{r}-0.0223 \quad(0.0041) \\
p=0.0000\end{array}$ & $\begin{array}{c}0.0274 \quad(0.0092) \\
p=0.0028\end{array}$ & $\begin{array}{c}0.0275 \quad(0.0054) \\
p=0.0000\end{array}$ & $\begin{array}{r}-0.0082 \quad(0.0110) \\
p=0.4539\end{array}$ & $\begin{array}{c}0.0055 \quad(0.0028) \\
p=0.0513\end{array}$ & $\begin{array}{r}0.0086 \quad(0.0050) \\
\rho=0.0835\end{array}$ \\
\hline 5th Principal Component & $\begin{array}{r}0.0067 \quad(0.0046) \\
p=0.1491\end{array}$ & $\begin{array}{c}-0.0042 \quad(0.0093) \\
p=0.6534\end{array}$ & $\begin{array}{r}-0.0041 \quad(0.0051) \\
p=0.4212\end{array}$ & $\begin{array}{r}0.0021 \quad(0.0115) \\
p=0.8545\end{array}$ & $\begin{array}{r}0.0008 \quad(0.0029) \\
p=0.7942\end{array}$ & $\begin{array}{r}0.0375 \quad(0.0042) \\
p=0.0000\end{array}$ \\
\hline 6th Principal Component & $\begin{array}{r}-0.0243(0.0040) \\
p=0.0000\end{array}$ & $\begin{array}{r}-0.0169(0.0092) \\
p=0.0656\end{array}$ & $\begin{array}{r}-0.0136(0.0057) \\
p=0.0168\end{array}$ & $\begin{array}{r}0.0058 \quad(0.0108) \\
p=0.5918\end{array}$ & $\begin{array}{r}-0.0091 \quad(0.0027) \\
p=0.0009\end{array}$ & $\begin{array}{r}-0.0227 \quad(0.0048) \\
p=0.0000\end{array}$ \\
\hline 7th Principal Component & $\begin{array}{c}0.0032 \quad(0.0044) \\
p=0.4676\end{array}$ & $\begin{array}{c}-0.0305 \quad(0.0098) \\
p=0.0017\end{array}$ & $\begin{array}{c}0.0344 \begin{array}{c}(0.0053) \\
p=0.0000\end{array}\end{array}$ & $\begin{array}{r}-0.0024 \quad \begin{array}{c}(0.0100) \\
p=0.8134\end{array}\end{array}$ & $\begin{array}{r}-0.0065 \quad(0.0030) \\
p=0.0312\end{array}$ & $\begin{array}{r}0.0004 \quad(0.0044) \\
p=0.9225\end{array}$ \\
\hline 8th Principal Component & $\begin{array}{c}0.0169(0.0044) \\
p=0.0001\end{array}$ & $\begin{array}{r}0.0242 \quad(0.0102) \\
p=0.0175\end{array}$ & $\begin{array}{r}0.0020 \quad(0.0055) \\
p=0.7091\end{array}$ & $\begin{array}{r}0.0177 \quad(0.0099) \\
p=0.0733\end{array}$ & $\begin{array}{r}-0.0026 \quad(0.0029) \\
p=0.3712\end{array}$ & $\begin{array}{r}0.0304 \quad(0.0044) \\
p=0.0000\end{array}$ \\
\hline 9th Principal Component & $\begin{array}{c}0.0182 \quad(0.0044) \\
p=0.0000\end{array}$ & $\begin{array}{r}0.0471 \quad(0.0088) \\
p=0.0000\end{array}$ & $\begin{array}{c}-0.0179(0.0050) \\
p=0.0004\end{array}$ & $\begin{array}{c}0.0333(0.0107) \\
\mathrm{p}=0.0017\end{array}$ & $\begin{array}{c}-0.0293 \quad(0.0029) \\
p=0.0000\end{array}$ & $\begin{array}{r}0.0086 \quad(0.0047) \\
p=0.0656\end{array}$ \\
\hline 10th Principal Component & $\begin{array}{c}-0.0067 \quad(0.0039) \\
p=0.0854\end{array}$ & $\begin{array}{c}-0.0331 \quad(0.0095) \\
p=0.0005\end{array}$ & $\begin{array}{c}0.0127 \quad(0.0050) \\
p=0.0107\end{array}$ & $\begin{array}{c}0.0359(0.0110) \\
\mathrm{p}=0.0011\end{array}$ & $\begin{array}{c}0.0023 \quad(0.0026) \\
p=0.3598\end{array}$ & $\begin{array}{r}-0.0047 \quad(0.0042) \\
p=0.2689\end{array}$ \\
\hline Grades Completed & $\begin{array}{r}0.0873(0.0026) \\
p=0.0000\end{array}$ & $\begin{array}{r}0.1521 \quad(0.0052) \\
p=0.0000\end{array}$ & $\begin{array}{r}0.0850 \quad(0.0029) \\
p=0.0000\end{array}$ & $\begin{array}{r}0.1011 \quad(0.0057) \\
\rho=0.0000\end{array}$ & $\begin{array}{r}0.0996 \quad(0.0016) \\
p=0.0000\end{array}$ & $\begin{array}{r}0.1149 \quad(0.0025) \\
p=0.0000\end{array}$ \\
\hline Potential Experience & $\begin{array}{c}0.0295(0.0016) \\
p=0.0000\end{array}$ & $\begin{array}{c}0.0264(0.0036) \\
p=0.0000\end{array}$ & $\begin{array}{r}0.0147(0.0020\}) \\
p=0.0000\end{array}$ & $\begin{array}{r}0.0424 \quad(0.0036) \\
p=0.0000\end{array}$ & $\begin{array}{c}0.0197 \quad(0.0011) \\
p=0.0000\end{array}$ & $\begin{array}{r}0.0333(0.0015) \\
p=0.0000\end{array}$ \\
\hline Region of Residence: North Central & $\begin{array}{r}-0.1688 \quad(0.0115) \\
p=0.0000\end{array}$ & $\begin{array}{r}-0.2183 \quad(0.0195) \\
p=0.0000\end{array}$ & $\begin{array}{r}-0.1679 \quad(0.0180) \\
p=0.0000\end{array}$ & $\begin{array}{r}0.0401 \quad(0.0301) \\
p=0.1838\end{array}$ & $\begin{array}{r}-0.1164 \quad(0.0059) \\
p=0.0000\end{array}$ & $\begin{array}{r}-0.1149 \quad(0.0086) \\
p=0.0000\end{array}$ \\
\hline Region of Residence: South & $\begin{array}{r}-0.1886 \quad(0.0093) \\
p=0.0000\end{array}$ & $\begin{array}{r}-0.2557 \quad(0.0163) \\
p=0.0000\end{array}$ & $\begin{array}{r}-0.1809 \quad(0.0134) \\
p=0.0000\end{array}$ & $\begin{array}{r}-0.1489 \quad(0.0228) \\
p=0.0000\end{array}$ & $\begin{array}{r}-0.1596 \quad(0.0057) \\
p=0.0000\end{array}$ & $\begin{array}{r}-0.0549 \quad(0.0088) \\
p=0.0000\end{array}$ \\
\hline Region of Residence: West & $\begin{array}{r}-0.0401 \quad(0.0141) \\
p=0.0044\end{array}$ & $\begin{array}{r}-0.0142(0.0250) \\
p=0.5711\end{array}$ & $\begin{array}{r}-0.1186 \quad(0.0129) \\
p=0.0000\end{array}$ & $\begin{array}{r}-0.0428 \quad(0.0233) \\
p=0.0661\end{array}$ & $\begin{array}{r}0.0032 \quad(0.0067) \\
p=0.6372\end{array}$ & $\begin{array}{r}-0.0034(0.0099) \\
p=0.7290\end{array}$ \\
\hline Local Unemployment Rate: $6 \%-9 \%$ & $\begin{array}{r}-0.0708 \quad(0.0102) \\
p=0.0000\end{array}$ & $\begin{array}{r}-0.0977 \quad(0.0177) \\
p=0.0000\end{array}$ & $\begin{array}{c}-0.0475 \quad(0.0134) \\
p=0.0004\end{array}$ & $\begin{array}{r}-0.0288 \quad(0.0240) \\
p=0.2299\end{array}$ & $\begin{array}{c}-0.0805 \quad(0.0063) \\
p=0.0000\end{array}$ & $\begin{array}{r}-0.0582 \quad(0.0087) \\
p=0.0000\end{array}$ \\
\hline Local Unemployment Rate: Over $9 \%$ & $\begin{array}{r}-0.0988 \quad(0.0125) \\
p=0.0000\end{array}$ & $\begin{array}{r}-0.1079 \quad(0.0211) \\
p=0.0000\end{array}$ & $\begin{array}{r}-0.1285 \quad(0.0129) \\
p=0.0000\end{array}$ & $\begin{array}{r}-0.1199 \quad(0.0244) \\
p=0.0000\end{array}$ & $\begin{array}{r}-0.1272 \quad(0.0072) \\
p=0.0000\end{array}$ & $\begin{array}{r}-0.1327 \quad(0.0096) \\
p=0.0000\end{array}$ \\
\hline National Unemployment Rate: $6 \%-9 \%$ & $\begin{array}{r}-0.0149 \quad(0.0126) \\
p=0.2389\end{array}$ & $\begin{array}{c}-0.0370 \quad(0.0211) \\
p=0.0795\end{array}$ & $\begin{array}{c}-0.0301 \quad(0.0151) \\
p=0.0466\end{array}$ & $\begin{array}{c}-0.0509 \quad(0.0270) \\
p=0.0597\end{array}$ & $\begin{array}{r}-0.0282 \quad(0.0074) \\
p=0.0001\end{array}$ & $\begin{array}{r}-0.0627 \quad(0.0102) \\
p=0.0000\end{array}$ \\
\hline National Unemployment Rate: Over $9 \%$ & $\begin{array}{r}-0.0224 \quad(0.0195) \\
p=0.2511\end{array}$ & $\begin{array}{r}-0.1266 \quad(0.0323) \\
p=0.0001\end{array}$ & $\begin{array}{r}-0.0386 \quad(0.0271) \\
p=0.1546\end{array}$ & $\begin{array}{r}-0.0159 \quad(0.0431) \\
p=0.7127\end{array}$ & $\begin{array}{r}-0.0227 \quad(0.0120) \\
p=0.0583\end{array}$ & $\begin{array}{r}-0.0607(0.0157) \\
p=0.0001\end{array}$ \\
\hline Year & $\begin{array}{c}0.0041 \quad(0.0021) \\
p=0.0442\end{array}$ & $\begin{array}{c}0.0064(0.0037) \\
p=0.0808\end{array}$ & $\begin{array}{c}0.0204 \quad(0.0023) \\
p=0.0000\end{array}$ & $\begin{array}{r}0.0068 \quad(0.0040) \\
p=0.0910\end{array}$ & $\begin{array}{c}0.0174 \quad(0.0012) \\
p=0.0000\end{array}$ & $\begin{array}{r}0.0219(0.0017) \\
p=0.0000\end{array}$ \\
\hline R-squared & .26 & .25 & .26 & .21 & .27 & .28 \\
\hline
\end{tabular}

1. Table updated on December 12, 1997

2. Excluded category for region of resilence is northeast. Excluded calcgory for locel and nasional unemployment rate is less than $6 \%$. 

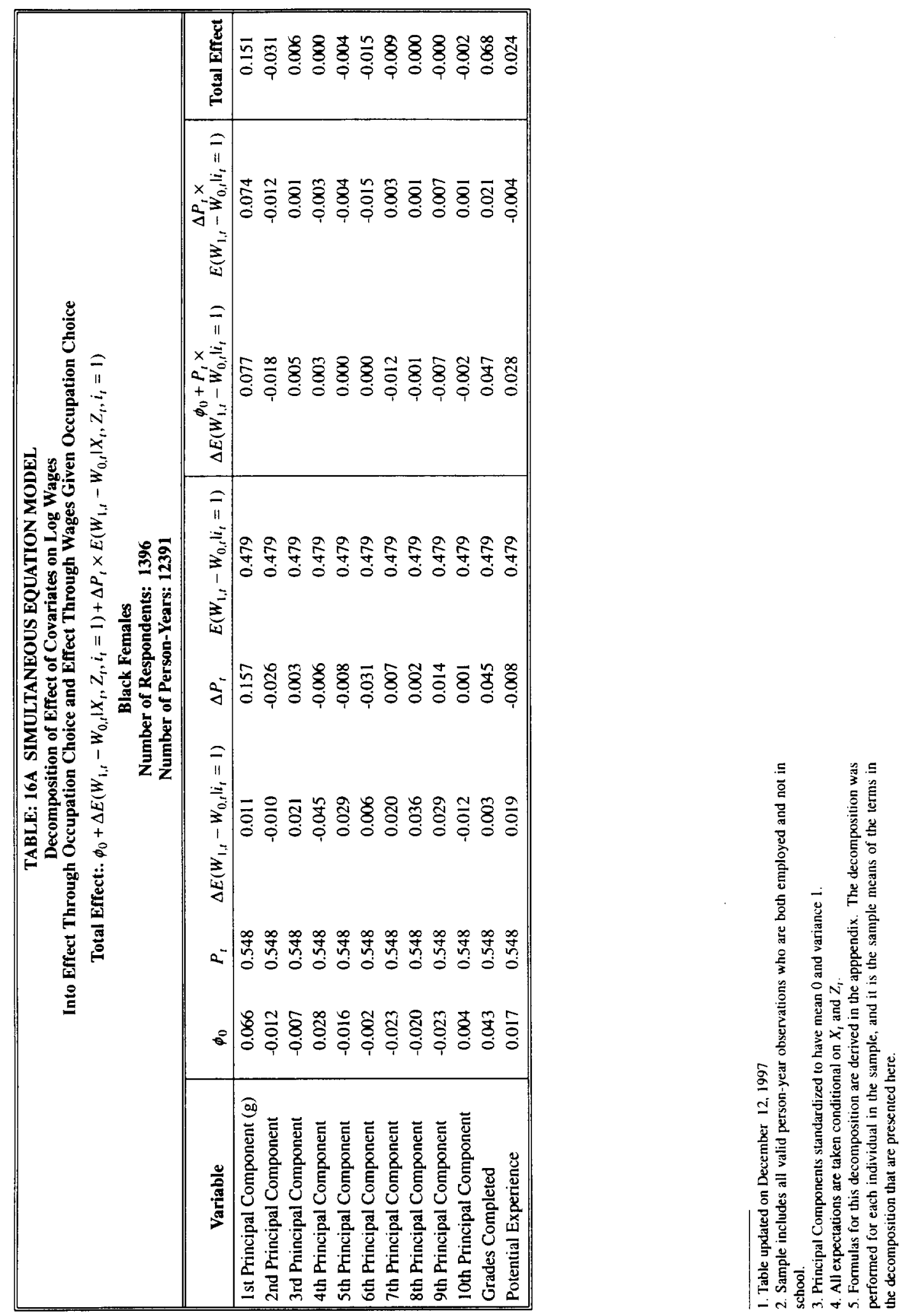